\title{
An Empirical Parameterization of Subsurface Entrainment Temperature for Improved SST Anomaly Simulations in an Intermediate Ocean Model
}

\author{
RONG-HUA ZHANG* \\ International Research Institute for Climate Prediction (IRI), The Earth Institute at Columbia University, Palisades, New York \\ RICHARD KLEEMAN \\ Courant Institute for Mathematical Studies, New York University, New York, New York \\ STEPHEN E. ZEBIAK \\ International Research Institute for Climate Prediction (IRI), The Earth Institute at Columbia University, Palisades, New York \\ NOEL KeENLySIDE \\ Max-Planck-Institut für Meteorologie, Hamburg, Germany \\ STEPHANE RAYNAUD \\ Courant Institute for Mathematical Studies, New York University, New York, New York
}

(Manuscript received 18 December 2003, in final form 19 July 2004)

\begin{abstract}
An empirical model for the temperature of subsurface water entrained into the ocean mixed layer $\left(T_{e}\right)$ is presented and evaluated to improve sea surface temperature anomaly (SSTA) simulations in an intermediate ocean model (IOM) of the tropical Pacific. An inverse modeling approach is adopted to estimate $T_{e}$ from an SSTA equation using observed SST and simulated upper-ocean currents. A relationship between $T_{e}$ and sea surface height ( $\mathrm{SSH}$ ) anomalies is then obtained by utilizing a singular value decomposition (SVD) of their covariance. This empirical scheme is able to better parameterize $T_{e}$ anomalies than other local schemes and quite realistically depicts interannual variability of $T_{e}$, including a nonlocal phase lag relation of $T_{e}$ variations relative to SSH anomalies over the central equatorial Pacific. An improved $T_{e}$ parameterization naturally leads to better depiction of the subsurface effect on SST variability by the mean upwelling of subsurface temperature anomalies. As a result, SSTA simulations are significantly improved in the equatorial Pacific; a comparison with other schemes indicates that systematic errors of the simulated SSTAs are significantly small-apparently due to the optimized empirical $T_{e}$ parameterization. Cross validation and comparisons with other model simulations are made to illustrate the robustness and effectiveness of the scheme. In particular it is demonstrated that the empirical $T_{e}$ model constructed from one historical period can be successfully used to improve SSTA simulations in another.
\end{abstract}

\section{Introduction}

Sea surface temperature (SST) over the tropical Pacific is one of the most important determinants of sea-

\footnotetext{
* Current affiliation: Earth System Science Interdisciplinary Center, University of Maryland, College Park, College Park, Maryland.

Corresponding author address: Rong-Hua Zhang, ESSIC, Computer and Space Science Bldg., No. 224, University of Maryland, College Park, College Park, MD 20742.

E-mail: rzhang@essic.umd.edu
}

sonal-to-interannual climate worldwide (e.g., McCreary and Anderson 1991; Neelin et al. 1992; Kleeman et al. 1996). In past decades, various models have been developed in an attempt to better describe and simulate SST variability of the region and its essential physics, but significant intermodel differences and some systematic model biases exist (e.g., Latif et al. 2001).

One of the most common uncertainties in SST modeling is the parameterization of entrainment and vertical mixing associated with subsurface temperature fields that affect SST variability significantly on interannual scales. Substantial progress has been made in parameterizing these processes for use in ocean models. 
Previously, numerous studies have focused on the determination of entrainment velocity across the base of the mixed layer (e.g., Chen et al. 1994; Wallcraft et al. 2003) and/or the coefficient of vertical diffusivity (e.g., Large et al. 1997; Large and Gent 1999; Canuto et al. 2001) for better simulation of upper-ocean temperature and current variability. Nevertheless, SST anomaly (SSTA) simulations in the region still remain a problem area for climate studies, with relatively large systematic errors in various models; errors in the coupling between entrainment temperature and SST variability continue to plague coupled models from the intermediate class to ocean general circulation models (OGCMs). Furthermore, the skill of SSTA simulation and prediction in the equatorial Pacific is strongly model dependent and widely divergent across various coupled prediction systems (e.g., Barnett et al. 1993; Chen et al. 1995, 2000, 2004; Ji et al. 1998; Stockdale et al. 1998; Latif et al. 1998; Barnston et al. 1999). Uncertainties in the parameterization of entrainment and vertical mixing continue to lower SSTA simulation and prediction skill in most state-of-the-art ocean models (Stockdale et al. 1998; Latif et al. 2001). Thus there is a substantial potential for improvement in SSTA simulation and prediction in the tropical Pacific Ocean.

In this work, we propose an alternative way to improve SSTA simulations through an optimized parameterization of subsurface effects (vertical advection, mixing, and entrainment) on the SSTA budget. Unlike previous parameterization schemes that improved the estimates of the entrainment velocity and/or the coefficient of vertical diffusivity coefficient, we focus on the temperature of subsurface water entrained into the mixed layer $\left(T_{e}\right)$, which can significantly affect SST variability through entrainment and vertical mixing. Indeed, determination of entrainment temperature at the base of the mixed layer is a great challenge for mixed layer modelers since the details of the temperature and density structure below the mixed layer and the mixed layer-thermocline interactions are not well known due to a lack of high-resolution observations in this region (e.g., Wang and McPhaden 2000). Furthermore, $T_{e}$ is not well observed; in fact, it is not precisely defined owing to the fact that a boundary between the mixed layer and the thermocline cannot be unambiguously determined in observations and in level ocean models.

Here, we develop an empirical procedure to estimate $T_{e}$ in terms of other ocean dynamical variables. First, we adopt an inverse modeling approach to estimate $T_{e}$ using an SSTA equation, observed SST, and simulated mean and anomaly currents. As such, for a given SSTA equation, the inverted $T_{e}$ anomalies, by balancing various terms in the heat budget of the mixed layer, yield an optimized estimate of $T_{e}$ for use in simulating SSTAs. Then, the relationship between $T_{e}$ anomalies and sea surface height (SSH) anomalies (directly available from a dynamical ocean model) is obtained by using a sin- gular value decomposition (SVD) of their covariance. The approach taken here is not to improve ocean models in terms of their realistic representation of the detailed temperature structure below the mixed layer down to the thermocline but simply to capture the empirical relation between the thermocline movement and the entrainment temperature that is important to interannual SST variability in the equatorial Pacific Ocean. This approach is tested in a new intermediate ocean model (IOM) recently developed by Keenlyside and Kleeman (2002, hereafter KK).

The dynamical ocean model is an extension of the McCreary (1981) baroclinic modal model and includes spatially varying stratification and partial nonlinear effects. As a result, the model can well simulate the observed mean current structure over the tropical Pacific Ocean, including the equatorial undercurrent (EUC), and the seasonal variations of surface equatorial currents (Keenlyside and Kleeman 2002). In particular, the model realistically captures the phase and amplitude of the seasonal cycle of zonal currents, as well as the westward propagation of seasonal maxima in the eastern basin. Furthermore, a SST anomaly model is coupled to the dynamical component. Among other processes, the SST variability in the model is driven by ocean horizontal advection and vertical advection associated with (prescribed) mean and (simulated) anomalous currents. One crucial component with such an IOM is the determination of $T_{e}$ (e.g., Zebiak and Cane 1987, hereafter ZC87; Perigaud and DeWitte 1996; Kang and Kug 2000; DeWitte et al. 2002). Since a subsurface temperature field is not available from the IOM, it has to be parameterized in terms of other ocean dynamic quantities, as in ZC87. In the original KK model, a local relation between $T_{e}$ and the $20^{\circ} \mathrm{C}$ isotherm depth was developed from modeled and observed data to determine $T_{e}$ from SSH anomalies, serving as an interface between the SST and dynamical model components (Keenlyside 2001). The model was found to simulate well the interannual SST variability, particularly in the eastern equatorial Pacific.

In addition to a large computational advantage over comprehensive OGCMs, this new IOM shares some similar advantages with other IOMs (e.g., ZC87). One is the anomaly formulation for SST in which only perturbation fields are calculated explicitly, and the mean seasonal climatology is prescribed directly from observations (such as SST and vertical temperature gradient). This offers a potential advantage in reducing model biases associated with the mean ocean state. As demonstrated in ZC87, Kleeman (1993), and Keenlyside (2001), mixed layer entrainment effects within this anomaly framework can be parameterized reasonably well in terms of the thermocline depth anomalies. In particular, the performance of this IOM can be further improved significantly by adopting an empirical $T_{e}$ parameterization scheme, which is detailed in this paper. 
The paper is organized as follows. Section 2 briefly describes the model and some observational data used in this work. Section 3 examines the performance of SSTA simulations in the tropical Pacific. A new empirical parameterization of $T_{e}$ is presented in section 4 . Section 5 demonstrates its effect on SSTA simulations, and section 6 deals with some validation experiments of the proposed $T_{e}$ parameterization scheme. The paper is concluded in section 7 .

\section{Model descriptions and observational data}

\section{a. An intermediate ocean model (IOM)}

Since IOMs remain competitive with more complex models and offer great promise for further advancing seasonal-to-interannual climate studies associated with El Niño, they are widely used in SSTA simulations and predictions (e.g., ZC87; Chen et al. 1995, 2000, 2004; Kleeman 1993; Perigaud and DeWitte 1996; Kang and Kug 2000; DeWitte et al. 2002). However, traditional IOMs (e.g., Busalacchi and O'Brien 1980; ZC87) include only a few baroclinic modes (often one) and neglect nonlinearity in the momentum equations, which can result in poor simulations of SST variability in the central Pacific where zonal advection is an important term in the heat budget (e.g., Ji et al. 1998). Increasing the number of baroclinic modes in these models improves the vertical structure of equatorial currents significantly (McCreary 1981). However, surface currents become unrealistically strong since nonlinear terms are neglected.

With these considerations, Keenlyside and Kleeman (2002) have recently developed a new IOM for the tropical ocean. The linear dynamics of the model follow the modal formulation of McCreary (1981) but with the further extension to having a horizontally varying background stratification. A nonlinear correction associated with vertical advection of zonal momentum is incorporated. A standard configuration is chosen whereby 10 baroclinic modes are retained, plus two surface layers that are governed by Ekman dynamics, simulating the combined effects of the higher baroclinic modes from 11 to 30 . The nonlinear component is applied (diagnostically) only within the two surface layers, forced by the linear part through nonlinear advection terms. The linear and nonlinear components produce dynamical ocean variables, including horizontal currents over the surface mixed layer, the vertical velocity at the base of the mixed layer (entrainment velocity), and ocean pressure fields. With these improvements, the model is able to realistically simulate the mean upper-ocean equatorial circulation and its variability (Keenlyside 2001; Keenlyside and Kleeman 2002).

The governing equation determining the evolution of interannual SST variability in the surface mixed layer can be written as (Keenlyside 2001)

$$
\begin{aligned}
\frac{\partial T^{\prime}}{\partial t}= & -u^{\prime} \frac{\partial \bar{T}}{\partial x}-\left(\bar{u}+u^{\prime}\right) \frac{\partial T^{\prime}}{\partial x}-v^{\prime} \frac{\partial \bar{T}}{\partial y}-\left(\bar{v}+v^{\prime}\right) \frac{\partial T^{\prime}}{\partial y} \\
& -\left[\left(\bar{w}+w^{\prime}\right) M\left(-\bar{w}-w^{\prime}\right)-\bar{w} M(-\bar{w})\right] \frac{\left(\bar{T}_{e}-\bar{T}\right)}{H} \\
& -\left(\bar{w}+w^{\prime}\right) M\left(-\bar{w}-w^{\prime}\right) \frac{\left(T_{e}^{\prime}-T^{\prime}\right)}{H}-\alpha T^{\prime} \\
& +\frac{\kappa_{h}}{H} \nabla_{h} \cdot\left(H \nabla_{h} T^{\prime}\right)+\frac{2 \kappa_{v}}{H\left(H+H_{2}\right)}\left(T_{e}^{\prime}-T^{\prime}\right) .
\end{aligned}
$$

Here $T^{\prime}$ and $T_{e}^{\prime}$ are anomalies of SST and the temperature of the subsurface water entrained into the mixed layer, $H$ is the depth of the mixed layer, $H_{2}$ is a constant $(125 \mathrm{~m}), M(x)$ is the Heaviside step function, and other variables are conventional. As expressed, the local rate of SST change (tendency) is controlled by horizontal advection, entrainment [the $M(x)$ terms], anomalous heat flux, horizontal diffusion, and vertical mixing, respectively. The surface heat flux is parameterized as being negatively proportional to the local SSTA $\left(\alpha T^{\prime}\right)$ with the thermal damping coefficient $\alpha=(100 \text { day })^{-1}$ estimated from data analyses (e.g., ZC87; Barnett et al. 1991). Note that $T_{e}$ is associated with two vertical processes: entrainment across the base of the mixed layer and mixing between the surface mixed layer and subsurface layer. The function $M(x)$ accounts for the fact that SSTAs are affected by vertical advection only when subsurface water is entrained into the mixed layer, but SSTAs can always be influenced by subsurface temperature variability through vertical mixing (the last term).

This SSTA model is embedded into the dynamical ocean model. In order to close the equation, $T_{e}$ needs to be determined from other ocean variables. Since the thermocline fluctuations in response to winds are a primary source of interannual variability of temperature throughout the upper ocean in the equatorial Pacific, $T_{e}$ in IOMs has been estimated in terms of thermocline depth anomalies for SSTA simulations (e.g., ZC87). In the KK model (Keenlyside 2001), a statistical local relationship between $T_{e}$ and SSH anomalies has been developed to parameterize $T_{e}$.

The ocean model domain extends from $33.5^{\circ} \mathrm{S}$ to $33.5^{\circ} \mathrm{N}, 124^{\circ}$ to $30^{\circ} \mathrm{E}$ in the tropical Pacific and Atlantic basins with a realistic representation of continents. (Only results from the Pacific basin are presented in this paper.) The model has a $2^{\circ}$ zonal grid spacing and a meridional grid stretching from $0.5^{\circ}$ within $10^{\circ}$ of the equator to $3^{\circ}$ at the meridional northern and southern boundaries. Obviously, the model has a coarse resolution, and the mesoscale eddies cannot be resolved in the model. A 5500-m flat-bottomed ocean is assumed since we are interested in large-scale processes that are important to SST variability in the tropical Pacific Ocean. The linear component has 33 levels at the standard ocean levels defined by Levitus (1982) with 8 lev- 
els in the upper $125 \mathrm{~m}$. The two layers used to simulate nonlinear effects and high-order baroclinic modes span the upper $125 \mathrm{~m}$ and are divided by a surface mixed layer whose depth is prescribed in terms of a stability criterion from the Levitus (1982) annual mean temperature and salinity data. The SSTA model has the same grid as the dynamical ocean model. At each time step (4800 s), the dynamical component calculates upper-ocean current and pressure anomaly fields; the corresponding $T_{e}$ anomalies are estimated from a SSH anomaly field. Together with prescribed climatologies of mean currents from the model and thermal fields from observations, they are all passed to the SSTA model to calculate its space-time evolution. Further details of the model configuration and parameters can be found in Keenlyside (2001) and Keenlyside and Kleeman (2002).

\section{b. An ocean general circulation model (OGCM)}

As a reference for assessing the performance of SSTA simulations and the $T_{e}$ parameterization, we also use the National Oceanic and Atmospheric Administration/Geophysical Fluid Dynamics Laboratory's (NOAA/GFDL) Modular Ocean Model (MOM3; Pacanowski and Griffies 1998), a comprehensive OGCM that provides three-dimensional temperature fields. Some newer features in the model include the implementation of a nonlocal $K$-profile parameterization (KPP) scheme for vertical mixing (Large et al. 1997; Large and Gent 1999). This advanced scheme allows better representation of interactions between subsurface and sea surface. In particular, the new MOM version with the KPP scheme allows the determination of the mixed layer depth, at which temperature variations can be correspondingly estimated. We have coupled this OGCM to an advective atmospheric boundary layer model (Seager et al. 1995) to estimate sea surface heat fluxes, allowing a realistic representation of the feedbacks between SST and the heat flux (e.g., Seager et al. 1995; Murtugudde et al. 1996; Zhang and Zebiak 2002). In addition, shortwave radiation is assumed to penetrate the upper layer with an $e$-folding depth of 12 m (Pacanowski and Griffies 1998). The OGCM domain covers the tropical Pacific basin from $30^{\circ} \mathrm{S}$ to $30^{\circ} \mathrm{N}$, $124^{\circ} \mathrm{E}$ to $80^{\circ} \mathrm{W}$, with horizontal resolution of $1^{\circ}$ latitude by $1^{\circ}$ longitude (but $0.33^{\circ}$ latitude between $10^{\circ} \mathrm{S}$ and $\left.10^{\circ} \mathrm{N}\right)$. It has 40 vertical levels with a constant $10-\mathrm{m}$ resolution in the upper $210 \mathrm{~m}$; the model incorporates realistic continents and bottom topography. Details of the model configuration and parameters can be found online (http://www.gfdl.gov/ mjh/IRI-ARCS), and in Zhang et al. (2001) and Zhang and Zebiak (2002). The OGCM, initiated from the Levitus (1982) temperature and salinity fields, is integrated for $10 \mathrm{yr}$ with climatological forcing fields, by which time it has achieved a near-equilibrium seasonal cycle, providing an initial condition for interannual experiments.

\section{c. Observational data}

Various observational data are used for constructing empirical relationships between anomaly fields as well as for verifying model simulations. Observed SST data are from Reynolds et al. (2002). Figure 1 shows the observed SSTAs along the equator from 1963 through 1996. Large SSTAs can be seen in the central and eastern equatorial Pacific. Monthly wind stress data are from the National Centers for Environmental Prediction-National Center for Atmospheric Research (NCEP-NCAR) reanalysis (Kalnay et al. 1996), and other atmospheric forcing fields necessary for the OGCM in the calculation of heat flux components through the atmospheric boundary model are also from the same NCEP-NCAR reanalysis products, including surface zonal wind velocity, meridional wind velocity, wind speed, cloud cover, sea surface air temperature and humidity, and solar radiation. Although the NCEP-NCAR reanalysis products have large biases, the complete datasets provide consistent atmospheric data necessary to calculate all forcing fields for the model. In addition, The Florida State University (FSU) wind data (Goldenberg and O'Brien 1981; Bourassa et al. 2001) are also used for some sensitivity experiments.

\section{The KK model simulation in the tropical Pacific}

Keenlyside (2001) has conducted extensive experiments with the new IOM, including simulations of current variations in the equatorial Pacific (Keenlyside and Kleeman 2002). In this section results from experiments with the IOM and the GFDL OGCM on simulating tropical Pacific SSTAs are presented. In both experiments, ocean models are forced by the same winds (NCEP-NCAR reanalysis).

For the KK model, we first carry out a mean run forced by seasonally varying NCEP-NCAR climatological winds from 1962 to 1999 to get mean currents; then we perform an interannual run. Since the model has been designed to also run in anomaly mode, interannual wind anomalies are directly used to produce anomalous ocean currents and pressure fields. Due to an obvious linear trend in the NCEP-NCAR reanalysis product, the wind anomalies from 1962 to 1999 have been detrended before being used to force the IOM. Using the original $T_{e}$ parameterization scheme implemented in the model (the KK scheme hereafter), $T_{e}$ anomalies can be estimated in terms of SSH anomalies. For the OGCM, total wind stress fields and other atmospheric forcing data are used to force the model during the period January 1948-April 2000 (Zhang et al. 2001). Monthly anomalies are then obtained relative to the corresponding model climatology that is derived from January 1948 to December 1999. Detailed comparisons among these models are beyond the scope of this paper.

Miller et al. (1993) made a detailed comparison of 

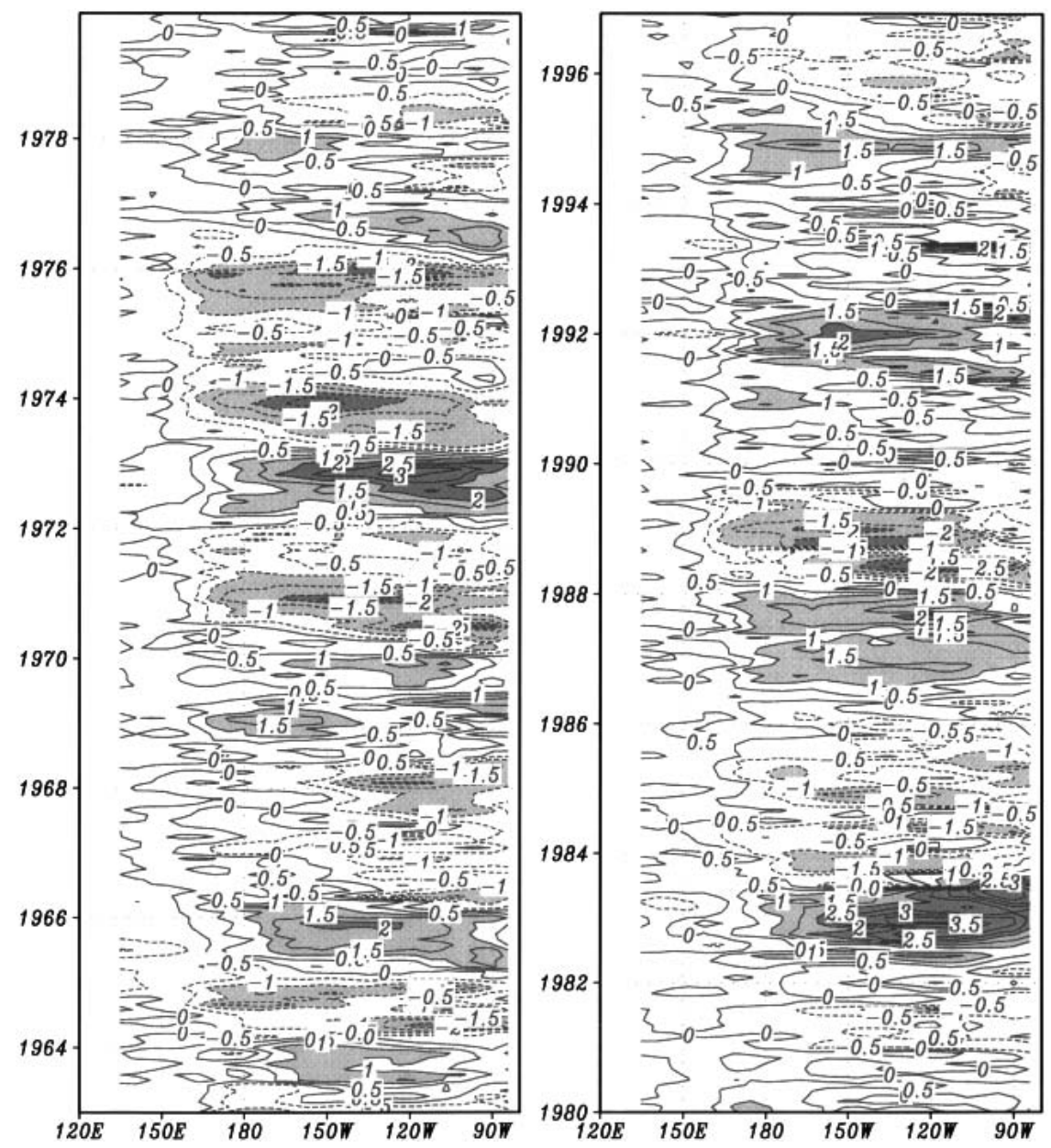

FIG. 1. Observed SST anomalies along the equator during the period 1963-96. Monthly mean data are from Reynolds et al. (2002). The contour interval is $0.5^{\circ} \mathrm{C}$.

SSTA simulations from various ocean models for the period 1970-1985. Model performance was evaluated in terms of anomaly correlation and root-mean-square (rms) error between modeled and observed SST anomalies (i.e., interannual anomalies are calculated relative to mean seasonal climatology). To allow a direct comparison of our results with Miller et al. (1993), we follow their analysis procedure: the same analysis period 1975-85 is adopted and a 5-month running mean of SSTAs is carried out before calculating correlation and rms error.

Figure 2 illustrates the simulated SSTAs along the equator from the standard KK model, as described in Keenlyside (2001). Interannual variability of SST is well reproduced over the eastern equatorial Pacific but is significantly underestimated in the central equatorial basin. The correlation and rms error between the simulated and observed SSTAs are shown in Fig. 3 for the period $1970-85$. The simulated SST variability is very good east of $150^{\circ} \mathrm{W}$, better than that of the OGCMs (e.g., Miller et al. 1993; Barnett et al. 1993). However, a problem exists in the central basin around the date line, where there are large errors in the SSTA simulation (Fig. 3b).

Compared with the OGCM simulations (see Miller et al. 1993), the spatial structure of SST variability in the KK model is quite different. The OGCMs tend to have the largest SST variability over the central equatorial Pacific, but relatively weak variability in the eastern basin. The IOM is the opposite: the simulated anomalies tend to be largest over the eastern equatorial $\mathrm{Pa}$ cific, but weak in the central basin (Fig. 2). These differences are typical of IOMs and OGCMs (e.g., Barnett et al. 1993), which reflect in effect a different degree of interactions between subsurface thermal field and SST in the two types of models. Since the KK model simulates the equatorial circulation as well as OGCMs (Keenlyside and Kleeman 2002), its deficiencies in underestimating SST variability over the central Pacific suggest that the $T_{e}$ parameterization may not be optimal.

To understand the nature of the problem, we show in Figs. $4 \mathrm{a}$ and $4 \mathrm{~b}$ the longitude-time sections along the 

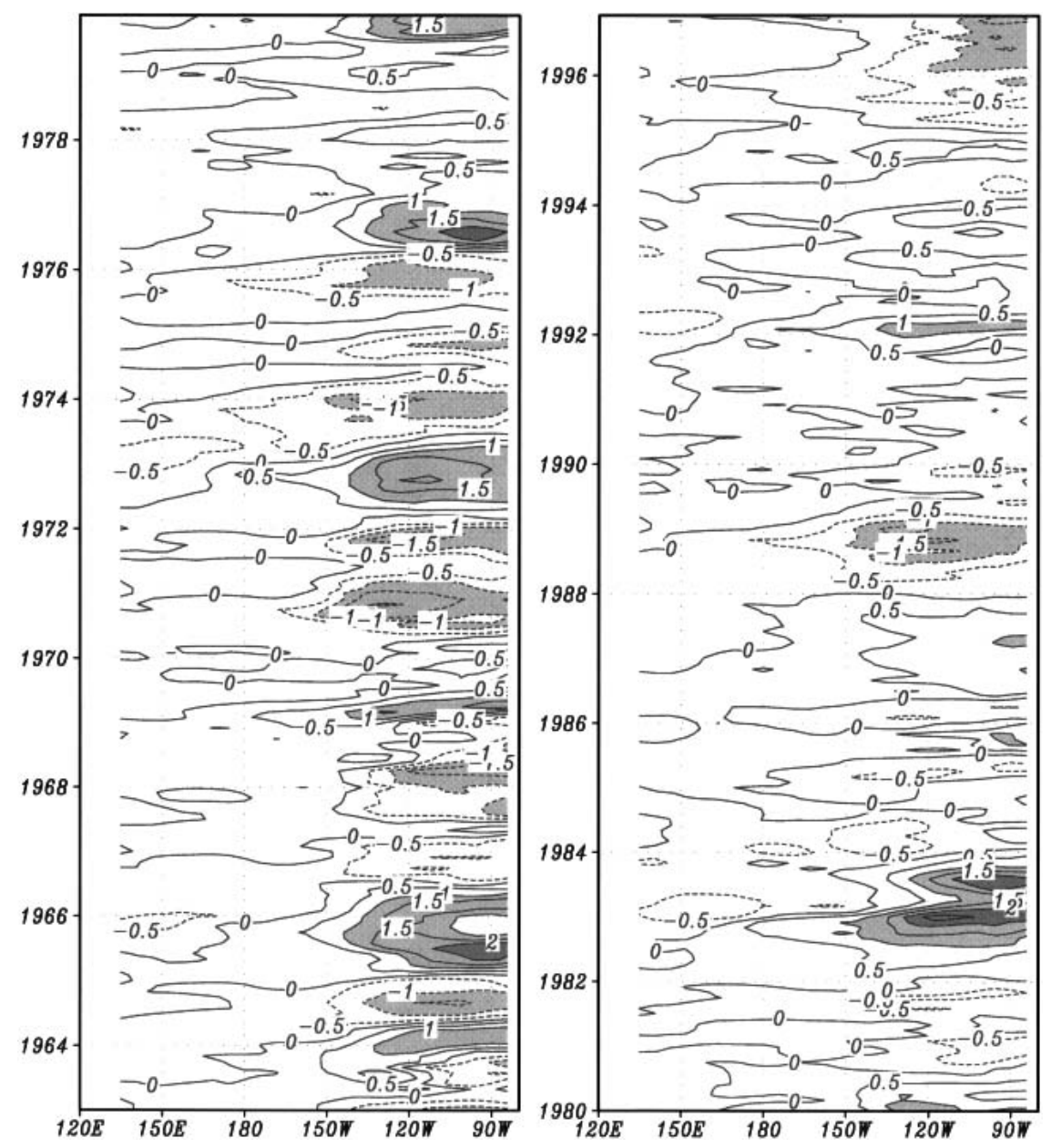

FIG. 2. Simulated SST anomalies along the equator during the period 1963-79 (left column) and 1980-96 (right column) from the KK model. The contour interval is $0.5^{\circ} \mathrm{C}$.

equator of the simulated SSH anomalies and parameterized $T_{e}$ anomalies from the original $\mathrm{KK}$ model. As a reference, we show in Fig. $4 \mathrm{c}$ the $T_{e}$ estimation from the OGCM; here, $T_{e}$ is defined as the temperature at the base of the mixed layer whose depth, varying in space and time, is estimated by the $k$-profile parameterization (KPP) scheme (Large and Gent 1999).

The $T_{e}$ anomaly fields estimated from the two models are strikingly different, in spatial structure, amplitude, duration, and in the phase relationship between the variations in $T_{e}$ and SSH [or equivalently sea level (SL) in the OGCM]. Some problems with the KK model are clearly evident in the $T_{e}$ fields (Fig. 4b) that are parameterized from SSH anomalies (Fig. 4a), as compared with those from the OGCM simulation (Fig. 4c). While the OGCM's $T_{e}$ anomalies are large both in the eastern and central basins, those of the KK model are concentrated predominantly in the east (largely east of $150^{\circ} \mathrm{W}$ ), with the simulated amplitude being significantly lower in the central basin near the date line (less than $\frac{1}{3}$ of the OGCM's).
We can take the evolution of the 1982-83 El Niño event as an example. Figure 5 shows one snapshot in January 1983 of SSH and $T_{e}$ anomalies from the KK model and $T_{e}$ anomalies from the OGCM, presenting the spatial structure at the mature stage of the event. The development of the 1982-83 El Niño is characterized by an eastward propagation of positive SSH anomalies along the equator (Fig. 4a). As the positive SSH signal propagates eastward along the equator across the date line, positive $T_{e}$ anomalies can be seen to emerge simultaneously in the central and eastern basins (east of $180^{\circ}$ ). In the KK model simulation, the parameterized positive $T_{e}$ anomalies are located too far eastward; large anomalies can only be seen east of $150^{\circ} \mathrm{W}$. Those in the central region (and the corresponding SSTAs, as shown in Fig. 2) are extremely weak. Furthermore, variations in $T_{e}$ follow those in SSH too tightly (Figs. 4a and 4b): once SSH anomalies become negative in the central basin (Fig. 5a), $T_{e}$ anomalies become negative immediately (Fig. 5b). This is evidently different from the OGCM simulations. 
(a) Correlation

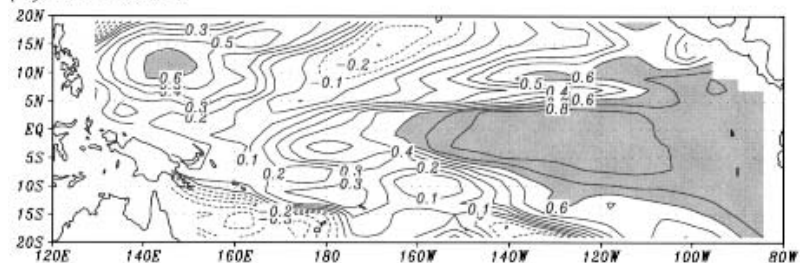

(b) RMS error

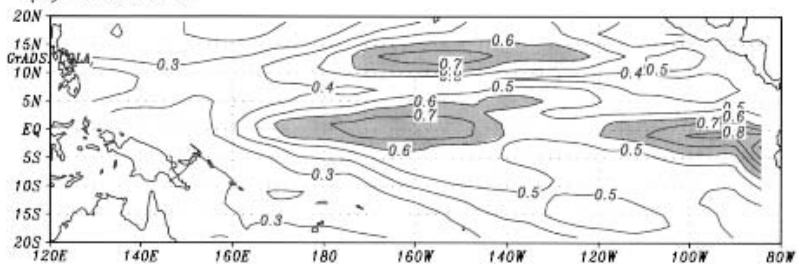

FIG. 3. Anomaly correlation and rms error between simulated and observed SST anomalies during the period 1970-85 from the KK ocean model. The time series at each point have been smoothed by a 5-month running mean filter. The contour interval is 0.1 .

The problem in the phase relationship between $T_{e}$ and SSH variations over the central equatorial Pacific is further illustrated in the time series at equator, $170^{\circ} \mathrm{W}$ during the period 1981-89 for simulated and param- eterized SSH and $T_{e}$ anomalies from the KK model, and anomalies of SL and $T_{e}$ from the OGCM, respectively (Fig. 6). Again, we take the 1982-83 El Niño evolution as an example. The SSH and SL in the equatorial band increase steadily over $2 \mathrm{yr}$ proceeding the warm event and rapidly decrease during the event. The thermodynamic response during the decay phase of the warm event, as manifested in $T_{e}$, is very different in the two model simulations. The $T_{e}$ anomalies from the KK model are not only weak, but are short lived over the central basin (Fig. 6a). Variations in $T_{e}$ almost exactly track SSH variations in the region: once the SSH anomalies have become negative, $T_{e}$ anomalies immediately become negative. In the OGCM simulations (Fig. 6b), the situation is different. Not only is the amplitude of $T_{e}$ variations over the central equatorial $\mathrm{Pa}$ cific larger, but there is a clear phase lag between $T_{e}$ and SL (Fig. 6b). These differences mean that at the mature stage of the 1982-83 El Niño, although SSH anomalies become negative in the central basin (around $160^{\circ} \mathrm{W}$ ), large positive $T_{e}$ anomalies still persist for more than 3 months in the OGCM [about $1^{\circ} \mathrm{C}$ in January 1983 near the date line on the equator (Fig. 5c), while in the $\mathrm{KK}$ model the $T_{e}$ anomalies are negative (about $-0.5^{\circ} \mathrm{C}$ in January 1983 (Fig. 5b)]. This indicates (a) $S S H$ from $K K$ model

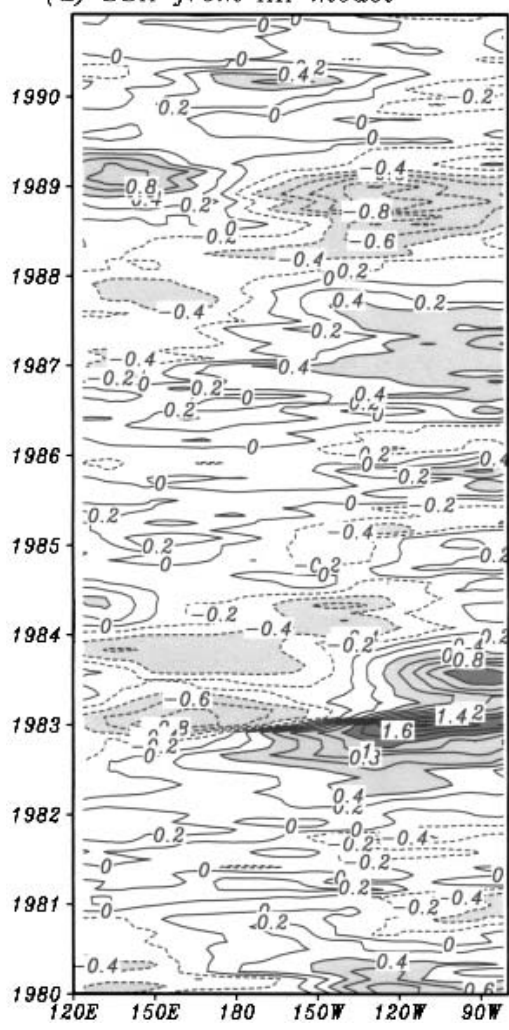

(b) $\mathrm{Te}$ from $\mathrm{KK}$ model

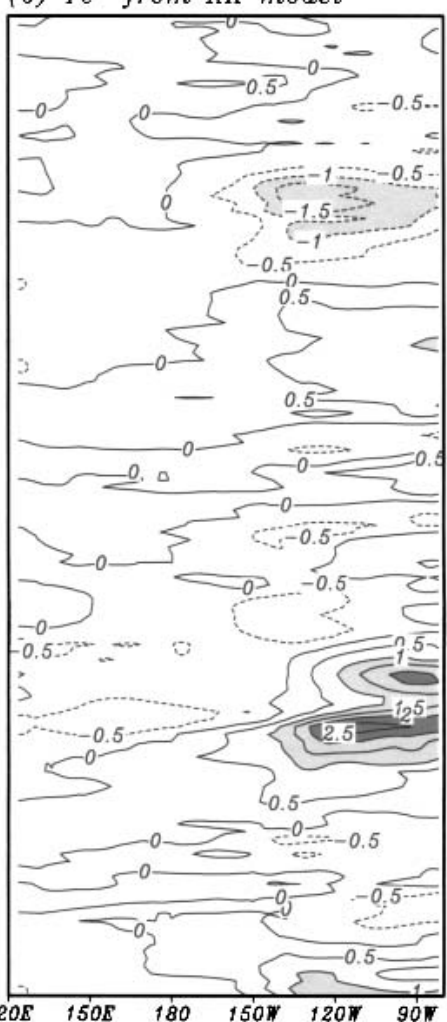

(c) Te from GFDL OGCM

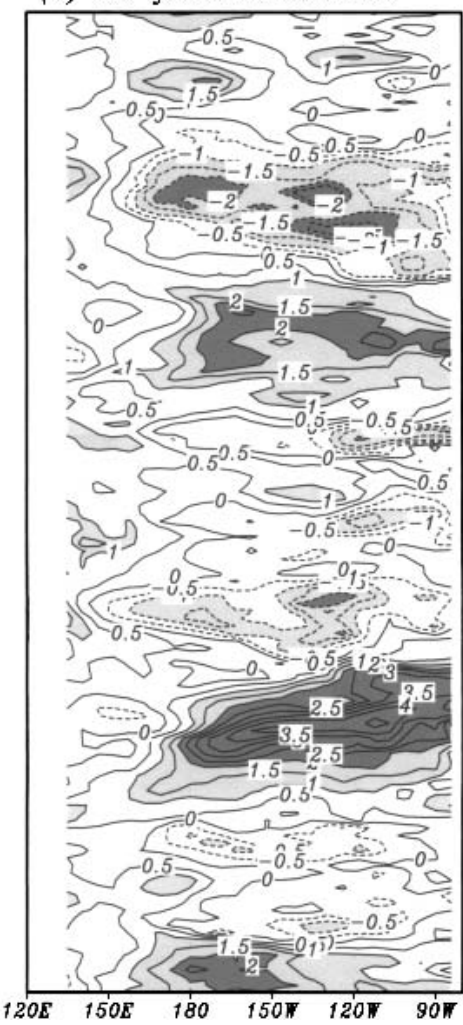

FIG. 4. Anomalies along the equator during period 1980-96 of (a) simulated SSH and (b) parameterized $T_{e}$ from the KK scheme, and (c) estimated $T_{e}$ from the NOAA/GFDL OGCM, respectively. The contour interval is $0.2 \mathrm{~m}^{2} \mathrm{~s}^{-2}$ in (a), and $0.5^{\circ} \mathrm{C}$ in (b) and (c). 

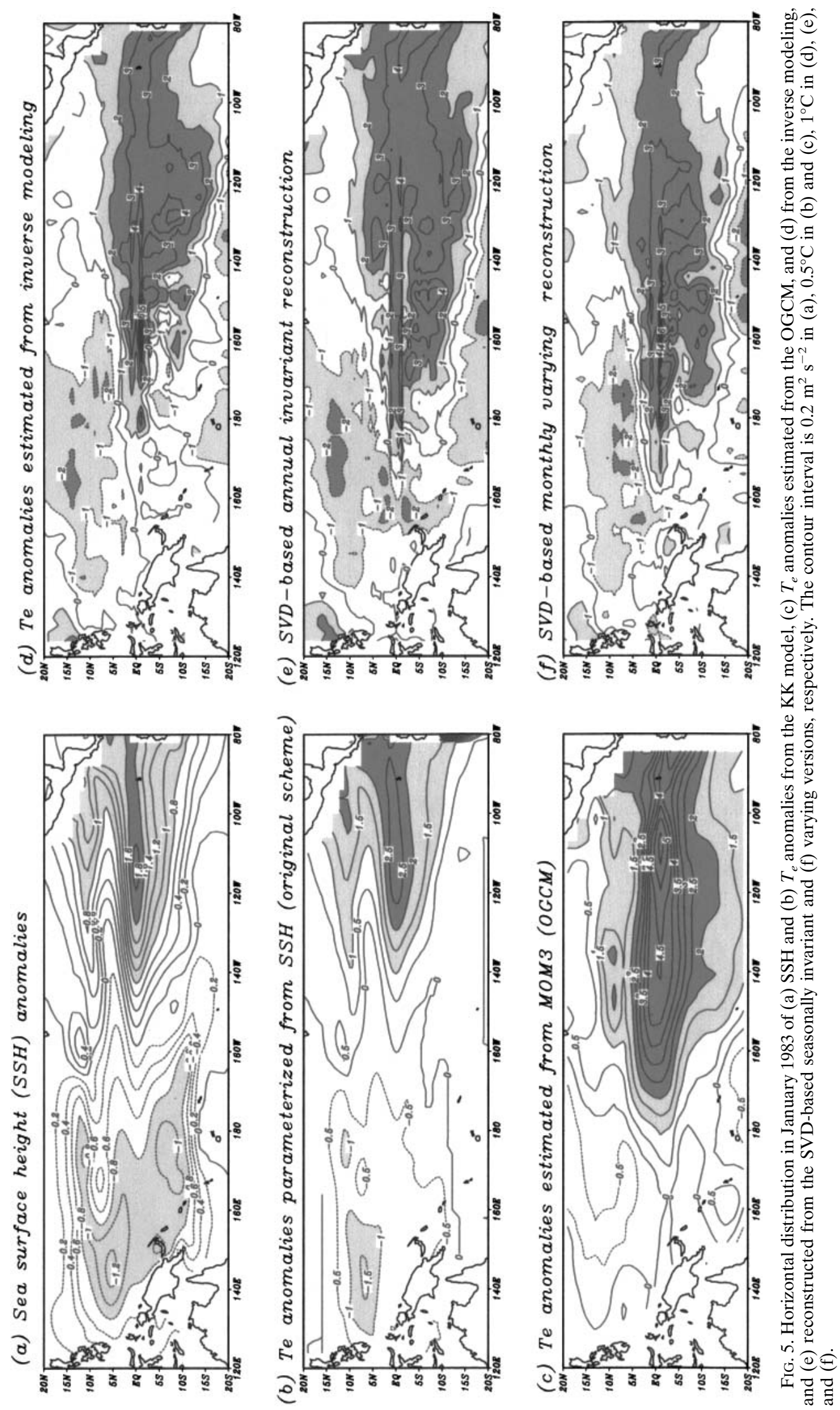

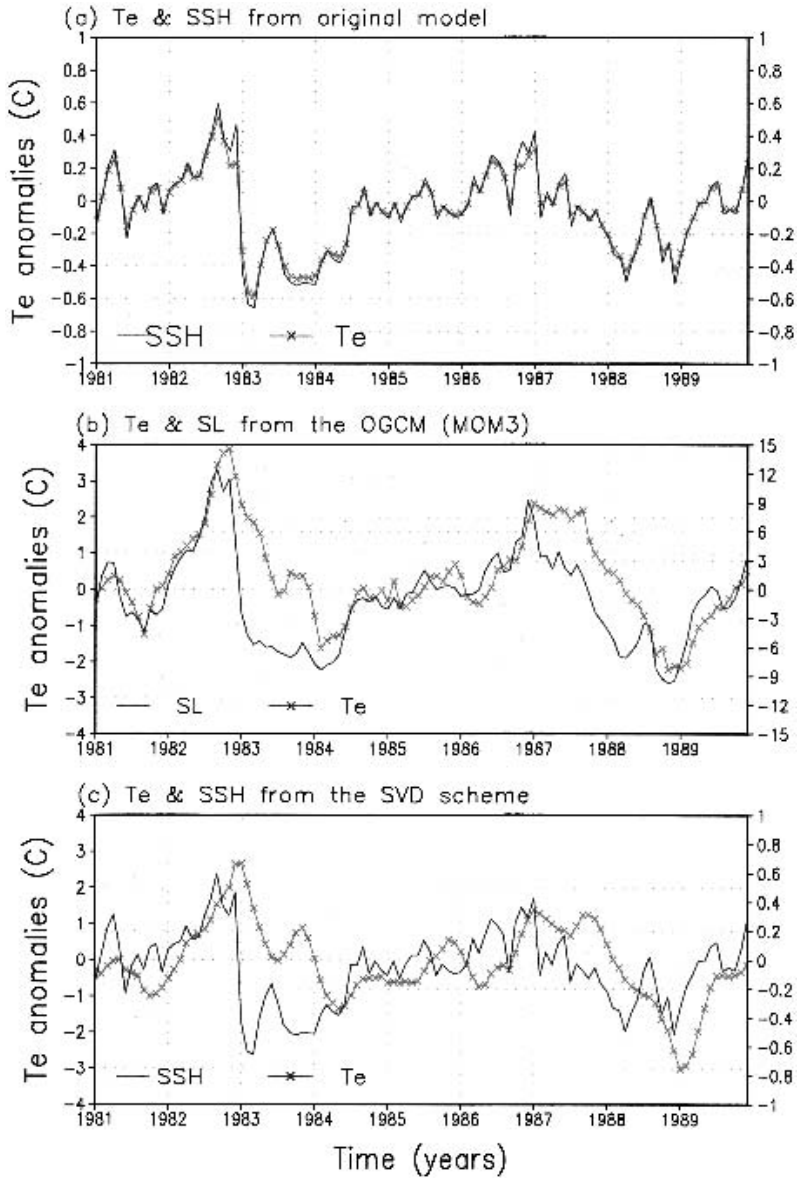

FIG. 6. Time series of simulated and/or parameterized anomalies from 1981 to 1989 at (equator, $170^{\circ} \mathrm{W}$ ) for (a) $\mathrm{SSH}$ and $T_{e}$ from the KK model, (b) SL and $T_{e}$ from the OGCM, and (c) for $\mathrm{SSH}$ and $T_{e}$ from the SVD-based invariant model. The vertical scales are on the left for $T_{e}\left({ }^{\circ} \mathrm{C}\right)$ and on the right for SSH $\left(\mathrm{m}^{2} \mathrm{~s}^{-2}\right)$ or SL $(\mathrm{cm})$.

that the relation between $T_{e}$ and the SL/SSH variability is not simply local.

Thus, in the KK model, the relative importance of subsurface temperature perturbations versus mixed layer current perturbations in determining SST variability will be underestimated due to the weakened $T_{e}$ variability over the central Pacific. As a result, SST variability over the central equatorial Pacific is weak (Fig. 2). The model's inability to capture the phase lag between $T_{e}$ and SSH variations causes the shorter duration of $T_{e}$ and SST anomalies over the central basin in the KK model than in the OGCM. It is thus not surprising that the KK model performs poorly in SSTA simulations over the central Pacific. Experiments with many tuning efforts in parameters and physics, including a better heat flux formulation, could not rectify this bias. Other $T_{e}$ parameterization schemes (e.g., the ZC87 local fitting scheme) have also been tested but did not significantly improve SSTA simulations either.

\section{An empirical $T_{e}$ parameterization scheme}

Data analyses and modeling studies indicate that the mixed layer entrainment is a primary process that causes SST variability in the central and eastern equatorial Pacific on interannual time scales (e.g., Cane and Zebiak 1985; ZC87; Neelin and Jin 1993; Jin and An 1999). The OGCM simulations, where $T_{e}$ can be directly estimated from subsurface temperature fields, clearly indicate that the entrainment temperature response at the base of the mixed layer to changes in ocean dynamics is very fast and almost simultaneous. Characterized by the vertical displacement of the thermocline, the ocean dynamical signal propagates very quickly within the equatorial wave guide, remotely generating a thermodynamic response at the base of the mixed layer. When the subsurface temperature anomalies entrain into the surface layer, SST variability can be produced. This understanding provides physical guidance for developing an alternative $T_{e}$ parameterization scheme that can be used in IOMs (e.g., ZC87; Kleeman 1993; Keenlyside 2001). We propose here a nonlocal empirical scheme to parameterize $T_{e}$ in terms of other dynamical fields.

In this section, we first describe an inverse modeling method for estimating $T_{e}$ anomalies since its geographic distribution and temporal evolution are not available from observations. Second, we propose a SVD-based scheme for estimating $T_{e}$ anomalies in terms of SSH anomalies. Finally, we present some validation results for the new scheme.

\section{a. An inverse modeling approach to estimating $T_{e}$}

The basic idea of inverse modeling is to use historical observational data, together with numerical models that are based on physical laws, to estimate parameters that are difficult to determine directly. The entrained temperature beneath the mixed layer is such a field. In the SSTA equation (shown above), $T_{e}$ is associated with two terms: entrainment by upwelling $\left[w\left(T_{e}^{\prime}-T^{\prime}\right)\right]$ and the vertical mixing between the surface mixed layer and subsurface layer $\left[k_{v}\left(T_{e}^{\prime}-T^{\prime}\right)\right]$, where $k_{v}$ is the vertical diffusion coefficient $\left(10^{-4} \mathrm{~m}^{2} \mathrm{~s}^{-1}\right)$. Since the SST tendency on the left side can be estimated from observational data (e.g., Fig. 1), it is possible to determine $T_{e}$ anomalies by inverting the SSTA equation using observed and model-produced data.

Using model outputs from the NCEP-NCAR wind run (mean and anomalous currents) and observed SST (Reynolds et al. 2002), $T_{e}$ anomalies can be estimated for the period 1962-99 in this manner. Figure 7 illustrates the $T_{e}$ anomalies along the equator during the period 1963-96. An example of the spatial structure of $T_{e}$ for January 1983 is shown in Fig. 5d. Although the field is "noisy," particularly in the western Pacific where SST variability is weak, large interannual variability can be clearly seen in association with El Niño and La Niña events. Reflecting very well observed SST 

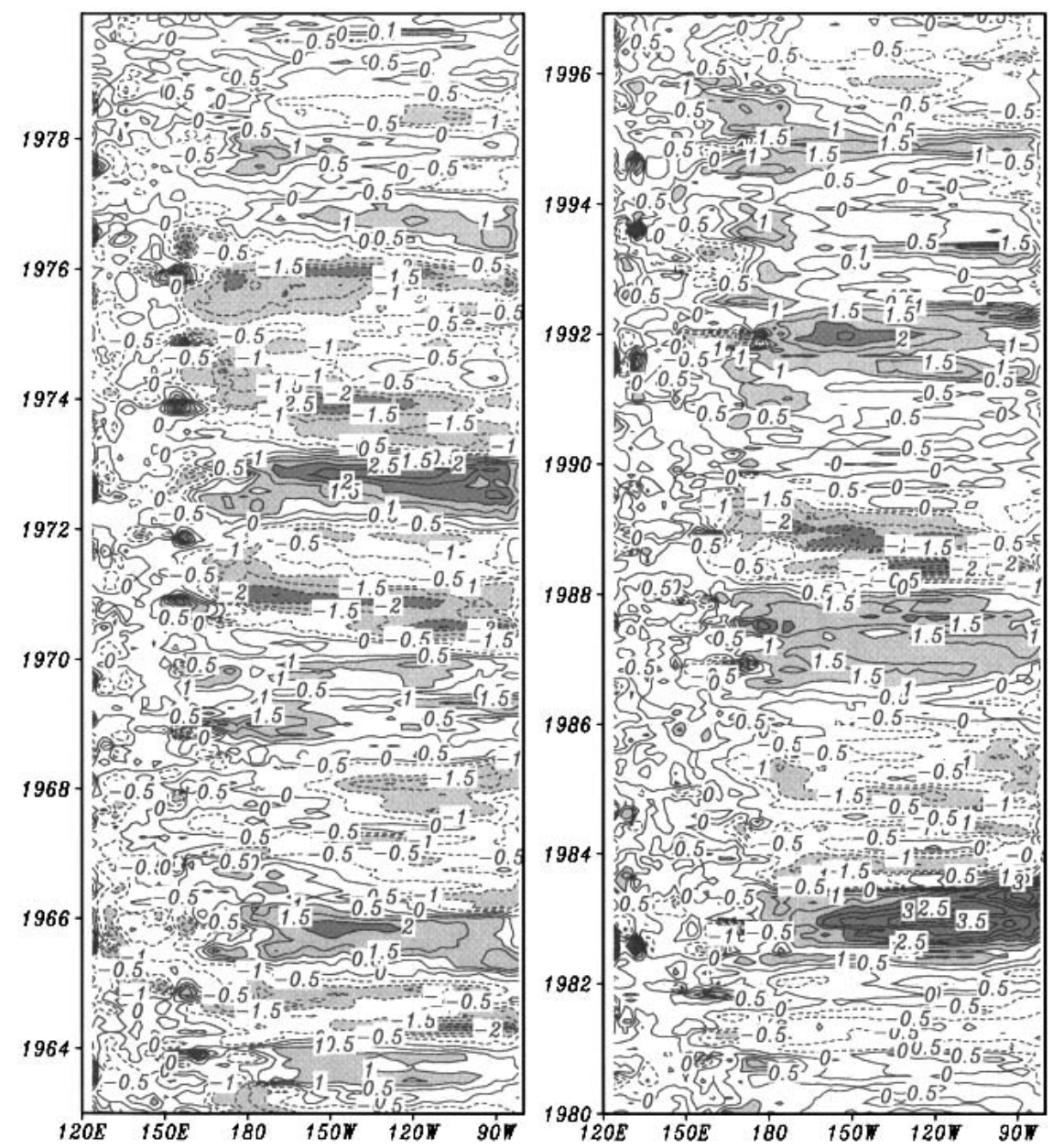

FIG. 7. Estimated $T_{e}$ anomalies along the equator during the period 1963-96 from the inverse modeling of the SST anomaly equation. The contour interval is $0.5^{\circ} \mathrm{C}$.

variability (Fig. 1), the $T_{e}$ anomalies have larger amplitude than those of SST, indicating the subsurface effect on SST variability is somehow tempered by other surface processes. The variability of the derived $T_{e}$ fields is in good agreement with that from the OGCM estimation (Figs. $4 \mathrm{c}$ and $5 \mathrm{c}$ ), in terms of structure and amplitude. However, there are significant differences between $T_{e}$ anomalies parameterized from the original KK scheme and from the inverse estimate (Fig. $4 \mathrm{~b}$ versus Fig. 7, and Fig. 5b versus Fig. 5d).

An important point to note is that $T_{e}$ anomalies calculated by this inverse method are, by definition, exactly those required by the SSTA model to perfectly simulate SSTAs. However, with this method, any systematic errors in terms that describe processes controlling SST changes (unresolved physics by the model, uncertainty in the model setting, and model errors in simulated ocean fields) are effectively lumped together in the derived $T_{e}$ field, possibly resulting in a biased estimate. Since vertical processes at the base of the mixed layer (entrainment and mixing), represented by
$T_{e}$, are the dominant processes affecting SST variability in the equatorial Pacific on interannual time scales, the aliasing problem may not be serious in the equatorial Pacific Ocean. As will be seen below, the $T_{e}$ estimation appears to be very reasonable since it is in good agreement with that from the OGCM. Furthermore, the feasibility of the approach is ultimately justified by its success in improving SSTA simulations. Given the present understanding of entrainment physics in the surface mixed layer and model limitations, the inverse modeling approach to estimating $T_{e}$ seems useful in terms of improved SSTA simulations (see below).

\section{b. An SVD-based relationship between $T_{e}$ and SSH variations}

Next, an empirical relation between $T_{e}$ and SSH anomalies is developed. To determine statistically optimized empirical modes of interannual variability between $T_{e}$ and SSH, a SVD analysis of the fields is performed. This statistical approach has been used widely and successfully to construct wind stress anomalies 
from SSTAs in many tropical coupled atmosphereocean models (e.g., Syu et al. 1995; Chang et al. 2001).

For our problem, this approach seems to be applicable. First, variations in SSH and $T_{e}$ are well correlated over the equatorial Pacific (Figs. 4 and 6). The origin of these correlations is the strong influence of ocean dynamical adjustments on $T_{e}$ (and SST) in the equatorial Pacific regions. As illustrated from the OGCM simulations (e.g., Fig. 4c), the entrainment temperature response at the base of the mixed layer to changes in SL (Fig. 6) is fast and almost simultaneous. Through the entrainment, the ocean dynamical adjustment in response to winds can have a direct and immediate effect on $T_{e}$ in the central and eastern equatorial Pacific.

More specifically, the empirical relationship between interannual $T_{e}$ and SSH variability is estimated using a SVD of the covariance matrix calculated from modeled time series of monthly mean $T_{e}$ and SSH anomalies. The SVD analysis adopted here is the same as that described in detail by Chang et al. (2001). Monthly data are first normalized by their spatially averaged standard deviation to form the covariance matrix. A SVD analysis is performed to get singular vectors, singular values, and the corresponding time coefficients. Two SVD calculations are possible. One version is called the seasonably invariant version (annual model): the SVD analysis is performed on all time series data irrespective of season. Another is called the seasonally varying version (monthly model): the SVD analysis is performed separately for each calendar month to construct seasonally dependent models giving 12 SVD models, one for each calendar month.

The SVD analysis was performed for the period 1963-96 (a total of $34 \mathrm{yr}$ of data) using SSH data from the interannual run forced by the NCEP-NCAR winds (Fig. 4a) and $T_{e}$ anomalies estimated from the same run (Fig. 7). For the invariant SVD analysis, we have a temporal sample of 408 points, while for the seasonally varying SVD analysis, we have a temporal sample of 34 points for each calendar month, marginal for giving stable statistics.

Figure 8 illustrates the singular values of mode 1-10 for the invariant SVD analysis of the covariance matrix calculated from time series of SSH and $T_{e}$ anomalies. The singular values represent the squared covariance accounted for by each pair of singular vectors. The first six singular values have values of about 2762, 592, 301, 230,170 , and 97 , with the squared covariance fraction of about $92.7 \%, 4.4 \%, 1.1 \%, 0.7 \%$ and $0.37 \%$, respectively. From the consideration of the sequence of the SVD singular values, and reconstructions of $T_{e}$ based on SSH anomalies, we chose to include the first five SVD modes in estimating $T_{e}$.

Figure 9 shows the spatial patterns derived from the first pair of singular vectors for SSH and $T_{e}$ and the associated time series. The temporal expansion coefficients (Fig. 9c) clearly indicate that the first mode de-

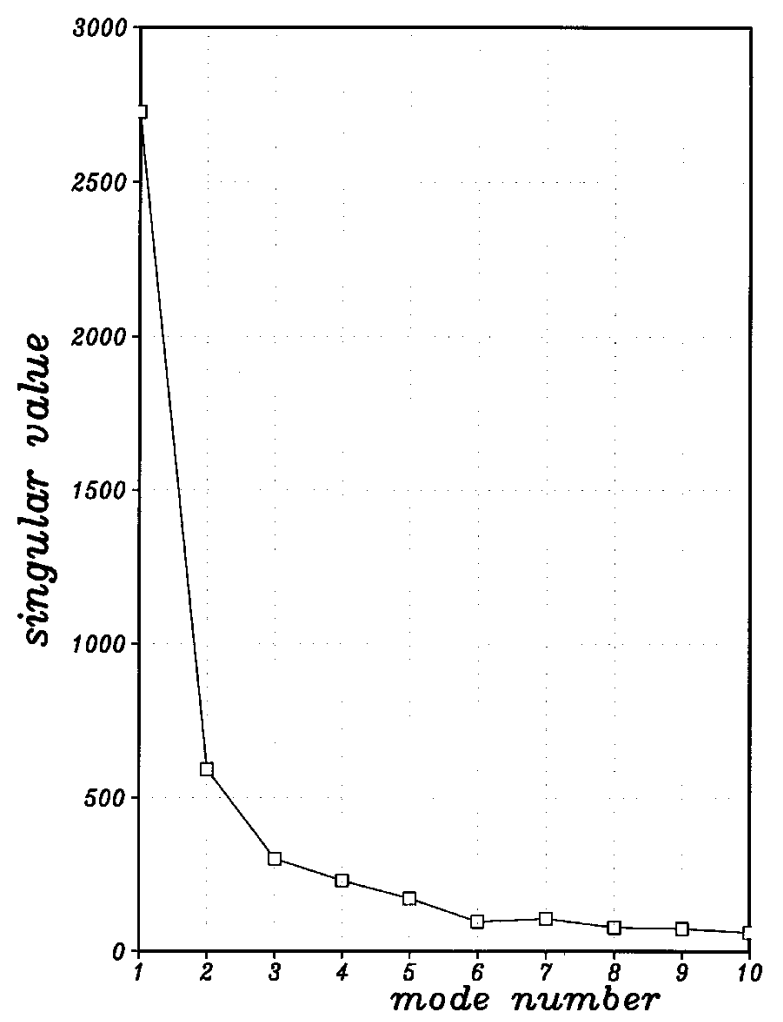

FIG. 8. Singular values of modes 1-10 of the SVD analysis of the covariance matrix calculated from time series of simulated SSH from the model and estimated $T_{e}$ from the inverse modeling of the SST anomaly equation.

scribes interannual variability associated with El Niño and La Niña events. The spatial structure represents the pattern of large-scale variability at the mature phase of El Niño or La Niña events, which can be readily verified in Fig. 5 for SSH and $T_{e}$ anomalies in January 1983. Clear differences are evident in the spatial structure of interannual anomalies between SSH and $T_{e}$. The SSH variability is characterized by a seesaw pattern across the basin: when one center is located in the eastern equatorial Pacific, another center with opposite polarity tends to be in the northwestern Pacific off the equator at $10^{\circ} \mathrm{N}$; the $T_{e}$ variability, on the other hand, is dominated by one center over the central equatorial Pacific around $170^{\circ} \mathrm{W}$. Thus, the variability centers of SSH and $T_{e}$ are not necessarily collocated, indicating the nonlocal nature of their space-time evolution. The higher modes (not shown) are typically smaller in amplitude and have less coherent structure in space and higher-frequency variability in time.

\section{c. Reconstruction of $T_{e}$ anomaly fields}

The $T_{e}$ anomalies can be reconstructed from SSH anomalies from the NCEP-NCAR wind run using the seasonally invariant and varying models. Figure 10a shows the $T_{e}$ anomalies reconstructed from the invari- 
(a) Spatial pattern of SSH anomalies

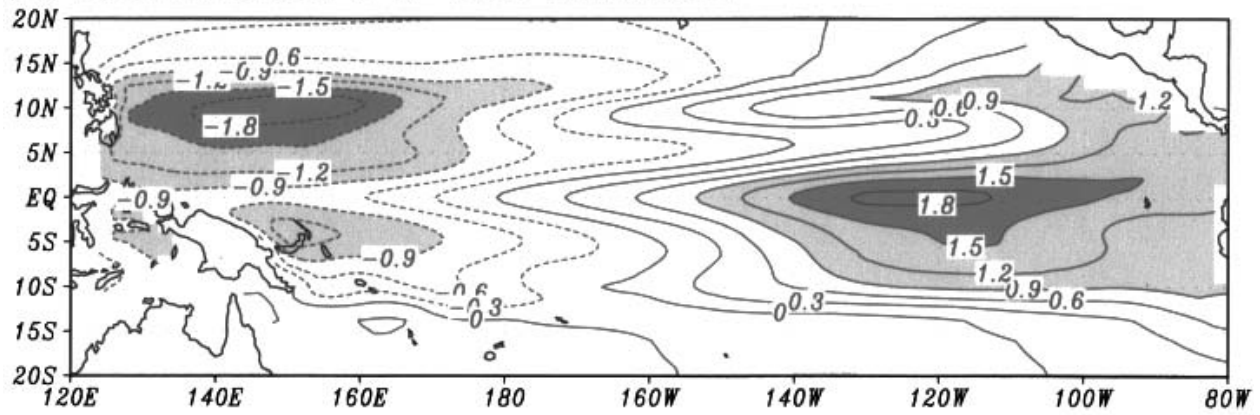

(b) Spatial pattern of Te anomalies

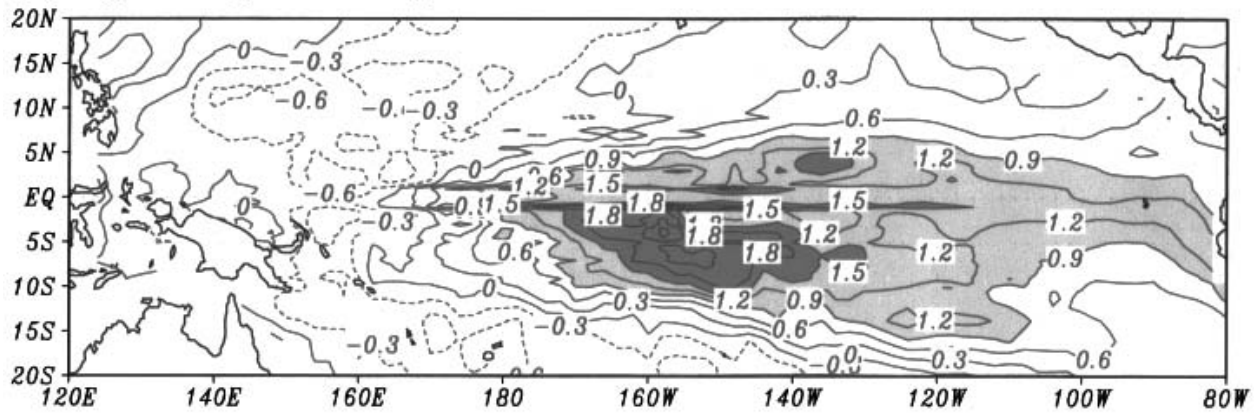

(c) Expansion coefficients

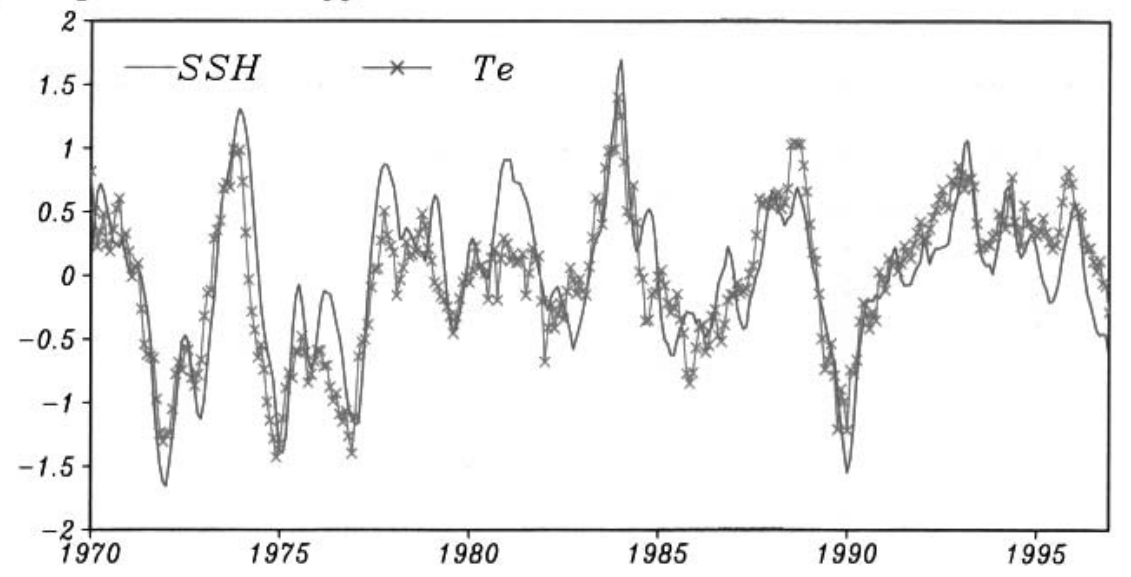

FIG. 9. Spatial patterns derived from the first pair of singular vectors for (a) SSH and (b) $T_{e}$, and (c) the time series associated with the first SVD mode. The contour interval is 0.3 in (a) and (b).

ant model for the period 1980-96 along the equator. Compared with the inverse model results (Fig. 7), the invariant model depicts very well large-scale interannual variability associated with El Niño and La Niña events. The amplitude of the reconstructed $T_{e}$ anomalies is comparable to the original field (Fig. 7), indicating the first five SVD modes are sufficient for recovering reasonable strength. However, the anomalies are somewhat smoothed and less noisy, indicating that the selected SVD modes effectively act as a low-pass filter.

It is instructive to compare the $T_{e}$ anomaly fields estimated from the original KK scheme (Fig. 4b), the
OGCM (Fig. 4c), the inverse model (Fig. 7), and the SVD-based reconstruction (Fig. 10). A detailed spatial distribution of the $T_{e}$ anomalies from these different estimates is shown in Fig. 5 for January 1983. Note that the original KK scheme and the SVD scheme both use the same SSH anomalies (Fig. 4a) as an input. Compared to the original $\mathrm{KK}$ scheme, the new scheme shows great improvements, both in terms of the amplitude and spatial structure, with significantly enhanced variability over the central equatorial basin. For example, as shown in Fig. 5e, in January 1983 the value of the parameterized $T_{e}$ anomalies is about $\sim 3^{\circ} \mathrm{C}$ over the 
(a) Annual invariant case

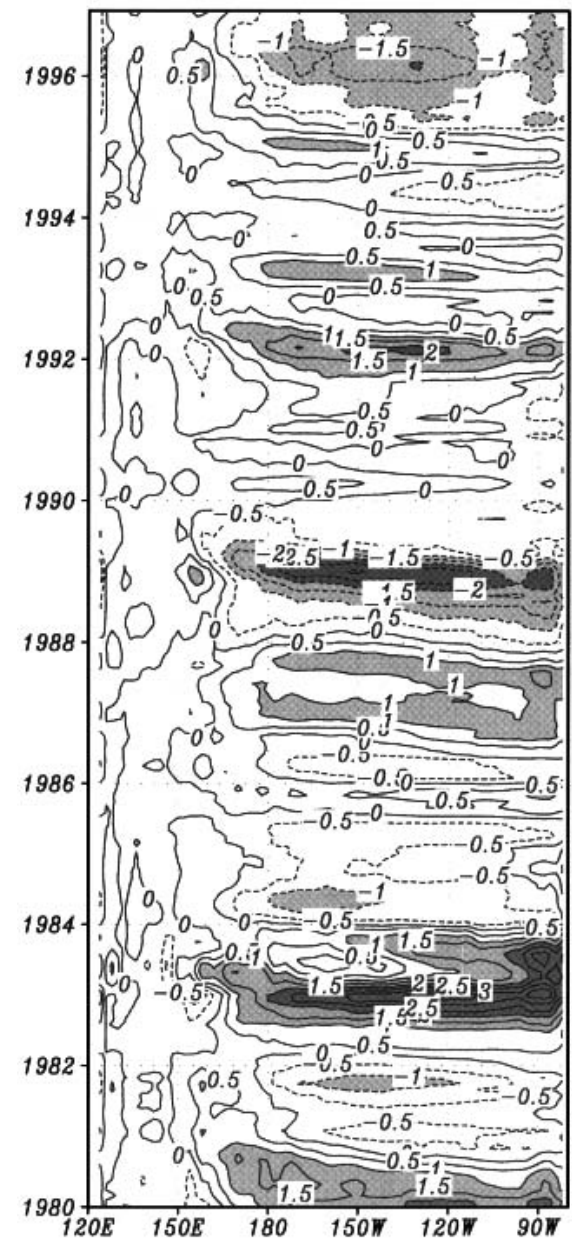

(b) Monthly varying case

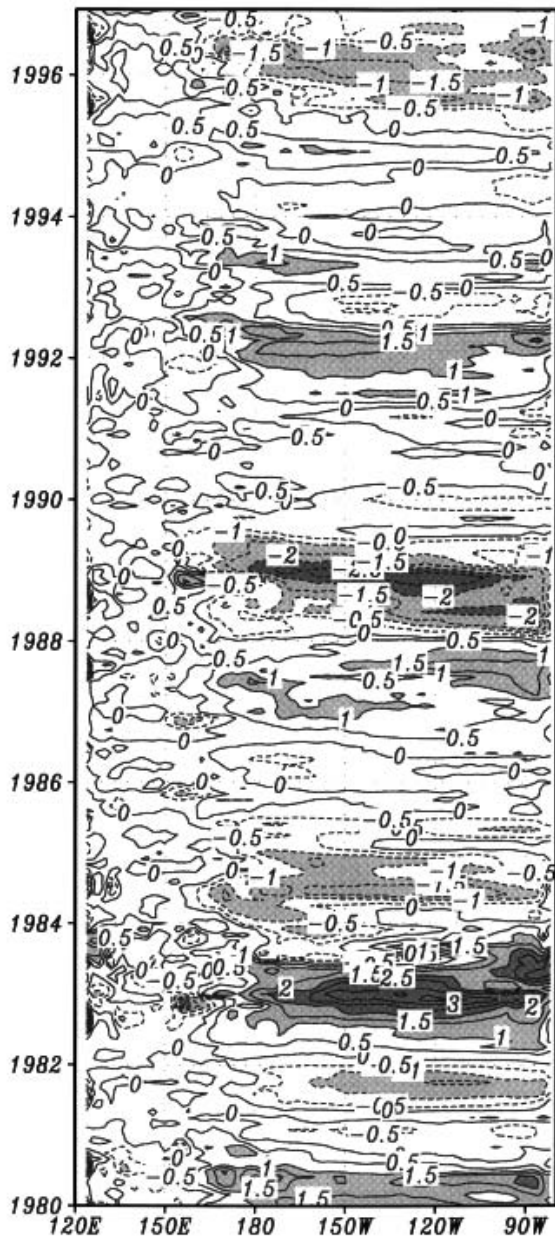

FIG. 10. Reconstructed $T_{e}$ anomalies along the equator during the period 1980-96 reconstructed from the SVD-based $\mathrm{T}_{\mathrm{e}}$ model in terms of SSH anomalies for the (a) seasonally invariant version and (b) the seasonally varying version. The contour interval is $0.5^{\circ} \mathrm{C}$.

central equatorial basin at $170^{\circ} \mathrm{W}$ with the new scheme, while it is $-0.5^{\circ} \mathrm{C}$ with the original $\mathrm{KK}$ scheme. Moreover, a temporal phase lag between variations in $T_{e}$ and SSH is realistically represented in the reconstructed $T_{e}$ field. As shown in Fig. 6, the time series of $T_{e}$ anomalies at $170^{\circ} \mathrm{W}$ show similar phase lag relative to $\mathrm{SSH}$ as seen in the OGCM simulations. During the mutual phase of the 1982-83 El Niño, although SSH anomalies become negative in the central basin, large positive $T_{e}$ anomalies persist for more than 3 months, attaining values of about $2^{\circ} \mathrm{C}$ in January 1983 on the equator near the date line (Fig. 5c).

As compared to the seasonally invariant model, the seasonally varying model reproduces the original fields somewhat better, including some smaller-scale and higher-frequency signals (Figs. 5f and 10b). Overall, however, the two statistical versions are quite comparable with each other in reproducing the original $T_{e}$ interannual variability obtained from the inverse modeling.

\section{An improved SSTA simulation in the tropical Pacific}

Using the new $T_{e}$ parameterization scheme, SSTA simulations forced by the NCEP-NCAR winds are now presented. Note that, in this section, we use the $T_{e}$ model that is trained during the period 1963-96. As such, the skill for SSTA simulations (e.g., as measured by the anomaly correlation) can be artificial, because of observational information of $T_{e}$ and SST variability covering the simulation period already being included in the training period.

\section{a. Seasonally invariant version}

Figure 11 presents the longitude-time sections of simulated SSTAs along the equator with the invariant version of the $T_{e}$ model. The effect of the new SVDbased $T_{e}$ parameterization on SSTA simulation is quite 

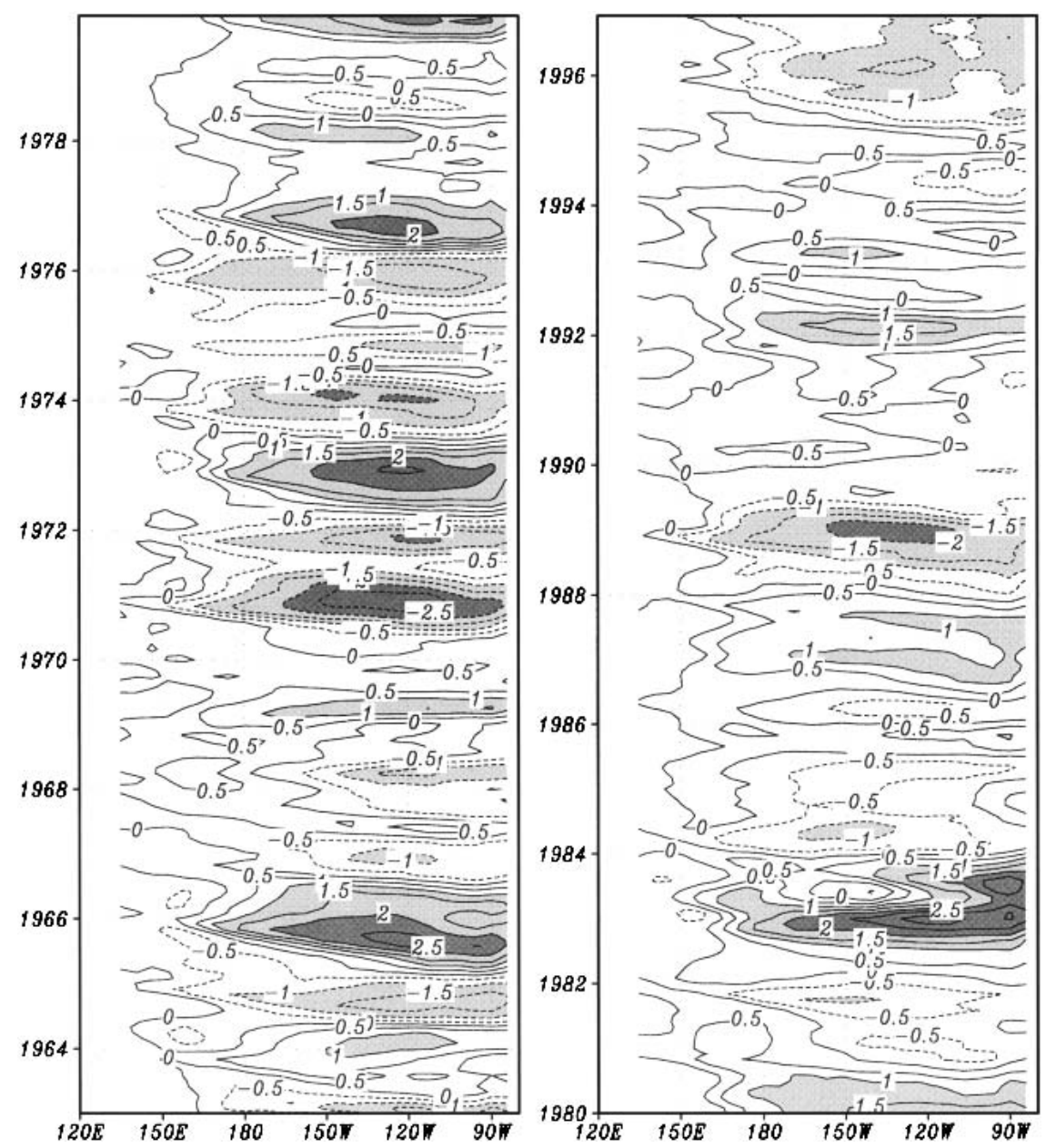

FIG. 11. Simulated SST anomalies along the equator during period 1963-79 (left column) and 1980-96 (right column) from the SVD-based invariant version of the $T_{e}$ model. The contour interval is $0.5^{\circ} \mathrm{C}$.

large, resulting in striking improvements over the entire tropical Pacific. Now, the simulated SST interannual variability is in good agreement with the observations (Fig. 1). In particular, the amplitude of the simulated SSTAs has increased significantly over the central equatorial Pacific due to the enhanced $T_{e}$ variability effect (Fig. 10a). As an example, Fig. 12 further displays the horizontal distribution of SSTAs for January 1983 observed from Reynolds et al. (2002) and simulated from the original KK scheme and from the SVD scheme (invariant version). Characterized by the mature phase of El Niño, the new scheme reproduces large and sustainable warm SSTAs over both the eastern and central Pacific. Figure 13 demonstrates the anomaly correlation and rms error during the period 1970-85. In terms of both measures, a basinwide improvement is clearly evident, as compared to the simulations presented by Miller et al. (1993) and as in Fig. 3. In the new simulation, correlation values exceeding 0.80 cover a broader region over the central and eastern equatorial
Pacific from $170^{\circ} \mathrm{E}$ to the coastal region of South America.

\section{b. Seasonally varying version}

Figure 14 represents the same plot as in Fig. 11 but from the seasonally varying version of the $T_{e}$ model. SSTA simulations are further improved relative to the invariant case. In particular, this version can resolve more detail of the space-time evolution of SST interannual variability, including the eastward migration of warm anomalies during El Niño events from the western Pacific (e.g., 1982-83 El Niño) and the westward spread of cold anomalies during La Niña events from the eastern basin (e.g., 1988-89 La Niña). The quantitative comparison for the two versions is demonstrated in Fig. 15, showing the correlation between simulated and observed SSTAs separately calculated during the period 1963-79 and during the period 1980-96, respectively. Overall, the seasonally varying version has better 
(a) Observitions

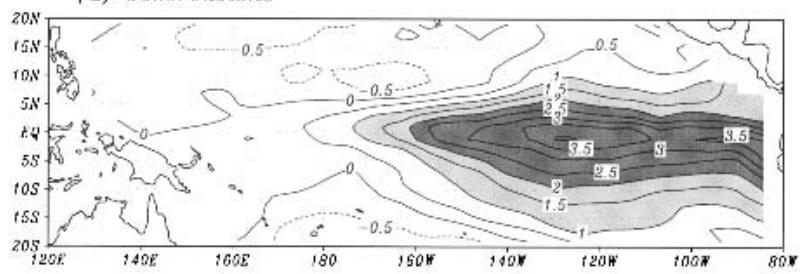

(b) Original Te parameletization

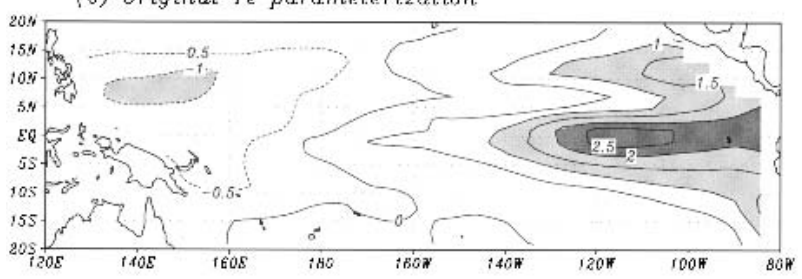

(c) SVD-bused annual invariant Te scheme

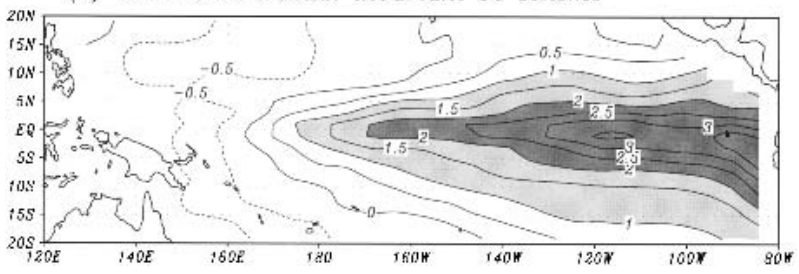

FIG. 12. Horizontal distribution of SST anomalies for January 1983 from (a) observations, (b) the original $T_{e}$ parameterization, and (c) the SVD-based invariant version of the $T_{e}$ model. The contour interval is $0.5^{\circ} \mathrm{C}$.

performance in terms of both correlation (Fig. 15) and rms error (not shown).

\section{Validation studies}

The SVD-based $T_{e}$ parameterization scheme presented above is empirical in nature and, as inherent to
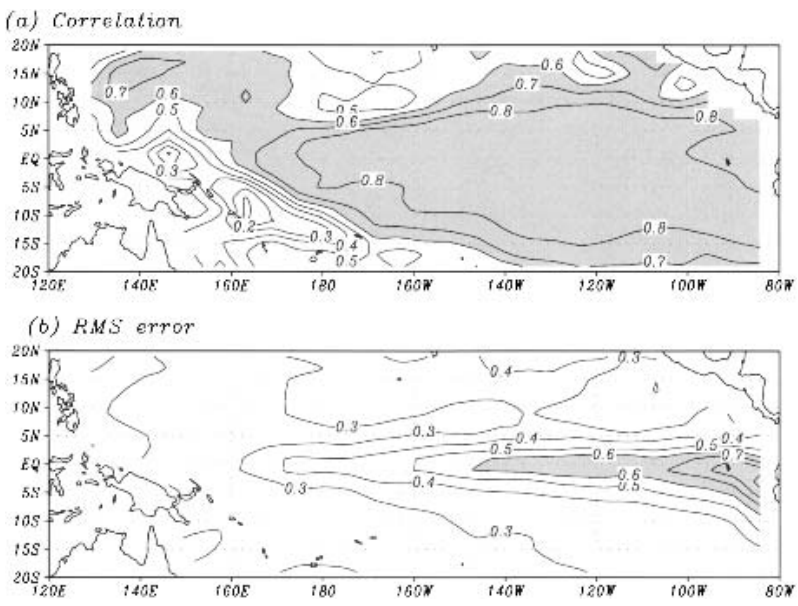

FIG. 13. (a) Anomaly correlation and (b) rms error between simulated and observed SST anomalies during the period 1970-85 with the SVD-based invariant version of the $T_{e}$ model. The time series at each point have been smoothed by a 5-month running mean filter. The contour interval is 0.1 . any statistical method, its performance can be sensitive to a variety of factors, including the period used to construct the $T_{e}$ model (the training period) and the period used to obey the model (the application period). It remains to be determined if the approach is strongly sensitive to the data periods selected for developing the $T_{e}$ model and for applying the model to SSTA simulations. Another important issue is the sensitivity of the $T_{e}$ model construction to the wind forcing used for the inverse calculation and for the simulations. A natural question is whether the SVD-based SSH- $T_{e}$ relationship established with the NCEP-NCAR winds can be used with comparable success in simulations forced by different wind products. In this section we will briefly examine these sensitivity issues to evaluate the effectiveness and robustness of the scheme in improving SSTA simulations.

\section{a. Cross-validation experiments}

Cross-validation experiments are performed by dividing the total analysis period, 1963-96 (a total of 34 yr), into two periods from 1963 to 1979 and from 1980 to 1996, constructing SVD-based $T_{e}$ models for both periods, and then applying both of these models to both periods. An experiment test is termed dependent (independent) when the $T_{e}$ model is constructed using data covering (not covering) the same period. One expects that the performance will be relatively good and skill will be relatively high if the application period overlaps the training period, but this may not be so when the application period does not overlap the training period. Thus, the cross-validated results can provide a more reliable estimate of skill improvement in SSTA simulations. Correlation and rms error between simulated and observed SSTAs during the two crossvalidation periods (both two dependent and independent cases) have been calculated using the seasonally invariant version of the SVD-based $T_{e}$ model. The cross-validation results for both periods are shown in Figs. 16 and 17, together with those from the original KK scheme.

As expected, the correlation values for the two dependent periods (Figs. 16b and 16e) are higher than those for the two independent periods (Figs. 16c and 16f). Correlation values exceeding 0.80 cover a broader region over the central and eastern equatorial Pacific from $170^{\circ} \mathrm{E}$ to the coastal region of South America. Correspondingly, the rms errors for the two dependent periods (Figs. 17b and 17e) are lower than those for the two independent periods (Figs. 17c and 17f); errors exceeding $0.7^{\circ} \mathrm{C}$ are located in a very narrow region in the far eastern equatorial Pacific. The performance for the two independent periods (Figs. 16c and 16f, Figs. 17c and 17f) is relatively poor, particularly in the far eastern equatorial Pacific. Nevertheless, the correlation obtained from the two independent cases (Figs. 16c and 16f) is still high as compared with that in Miller et al. (1993), with the values over 0.7 covering a broad area in 

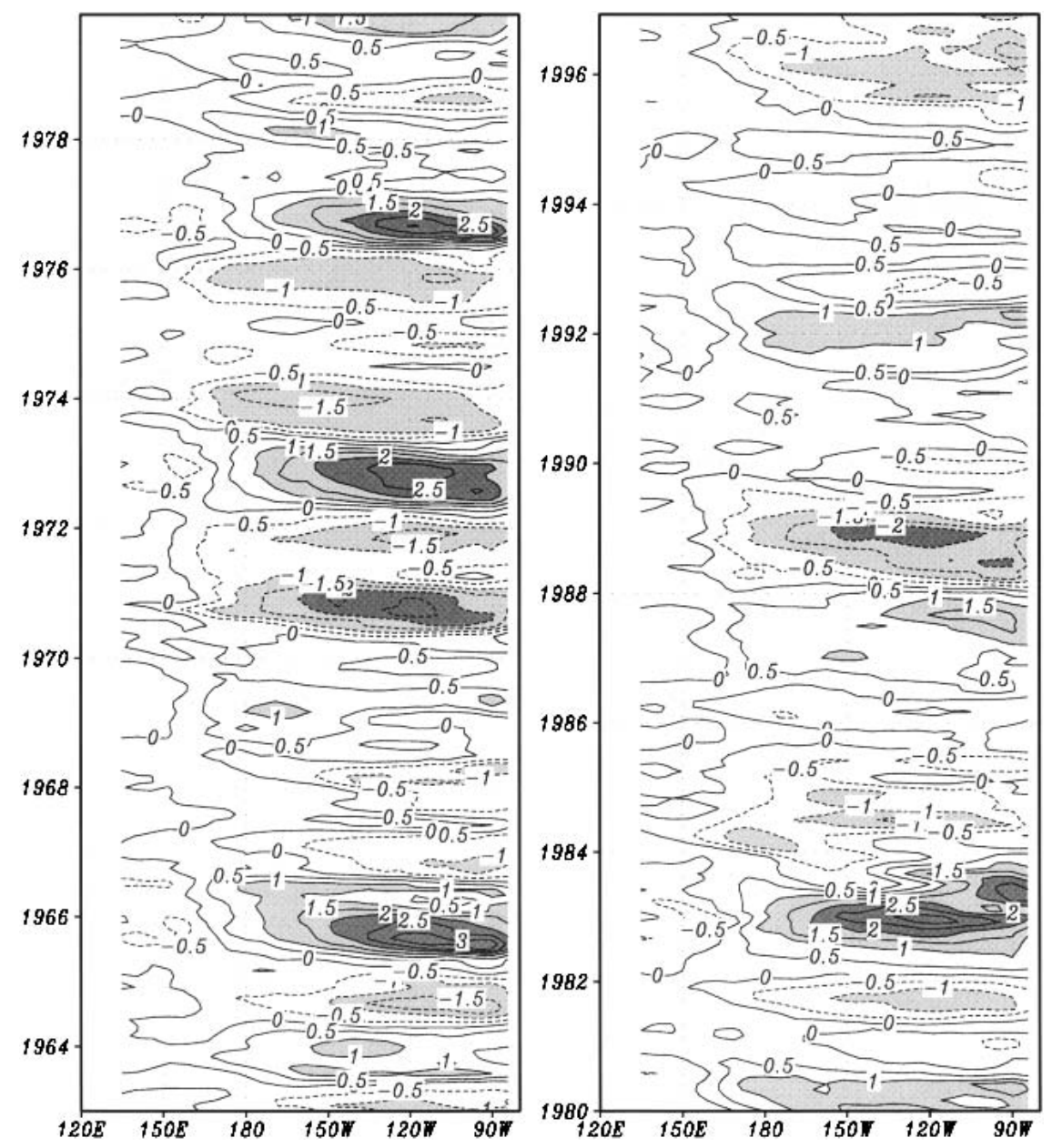

FIG. 14. As in Fig. 11, but for the seasonally varying version.

the central and eastern equatorial basin. Compared to the corresponding dependent cases, the correlation does not drop very much over most of the central equatorial Pacific.

Note that the cross-validation experiments we designed above are the strictest test of the $T_{e}$ parameterization scheme possible since totally independent historical data are used in constructing $T_{e}$ models for use in simulating SSTAs. As such, the results obtained during the two independent periods present the worst cases in terms of SSTA simulation skill. However, given the real ocean states between these two periods experienced significant decadal changes in the tropical $\mathrm{Pa}-$ cific, including subsurface thermal structure and SST (e.g., Kleeman et al. 1996; Zhang and Levitus 1997), these results are encouraging. This suggests that the performance of the new $T_{e}$ scheme is not unduly sensitive to the training period selected nor to the application. Although the periods selected for cross validations are too short to produce stable statistics for the SVD analysis, the empirical $T_{e}$ model appears to be very successful in improving SSTA simulations.

\section{b. Interannual run with the FSU winds}

As a sensitivity test, the SVD-based $T_{e}$ model established from the NCEP-NCAR winds is used to perform another interannual run forced by a different wind product - the FSU winds. Using the seasonally varying version, an integration is carried out to examine the performance of SSTA simulations forced by the latest FSU wind anomalies from January 1978 to December 2002 [Bourassa et al. (2001); see the Web site at http//: www.coaps.fsu.edu]. The FSU pseudostress data are converted into wind stress using a coefficient of $1.3 \times$ $10^{-3}$, with an air density of $1.2 \mathrm{~kg} \mathrm{~m}^{-3}$. Interannual wind anomalies are calculated relative to the mean climatology from 1974 to 2001 . The longitude-time sections of simulated SSTAs along the equator for the period 1980-96 are shown in Fig. 18a. Compared to the corresponding observations (Fig. 1), the simulated SST variability has reasonable amplitude and structure over the tropical Pacific. The quality of the SSTA simulations is quite comparable with those forced by the NCEP-NCAR winds (Fig. 14). Although the amplitude 

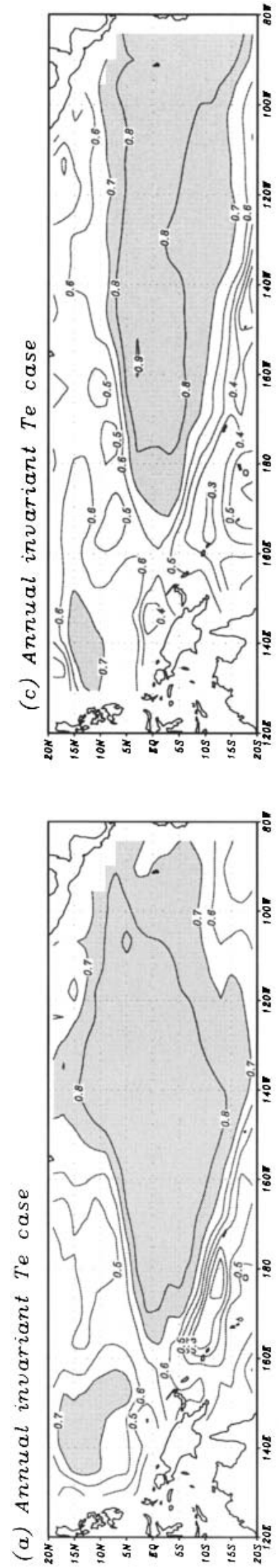

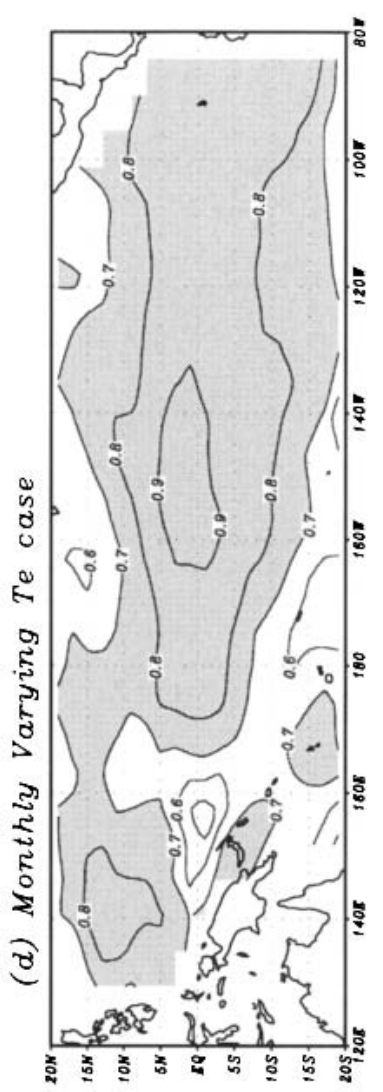

of SST interannual variability is slightly increased, as compared to the NCEP-NCAR wind simulations (Fig. 14), the results provide no indications of any imbalance in the SSTA equation, and the corresponding SSTA simulations do not show systematic bias. The correlation between simulated and observed SSTAs during the period 1980-96 (Fig. 19a) further shows that these results are very compatible to the NCEP-NCAR wind run (Fig. 15d).

\section{c. A simulation for the period 1997-2002 with the FSU winds}

Additionally, we present results for an interannual run forced by the FSU winds for the period 1997-2002. Here, the SVD-based $T_{e}$ model is constructed during the period 1963-96 using data from the interannual run forced by the NCEP-NCAR winds, but SSTA simulations are made by forcing the dynamical model with the FSU winds. This presents a challenge for the $T_{e}$ parameterization scheme as the simulation is independent of the data used in estimating $T_{e}$ in the inverse modeling, constructing the empirical model for $T_{e}$, and in training the $T_{e}$ model for winds. The simulated SSTAs along the equator during the period 1997-2002 (Fig. 18b) show no indication of systematic bias as compared to observations. Instead, the model successfully simulates the 1997-98 El Niño event and the following prolonged cold event. The amplitude of the 1997-98 El Niño event is well represented while the cold anomalies are slightly stronger. The anomaly correlation for the period from January 1997 to December 2002 (Fig. 19b) is comparable with other simulations shown above (e.g., Figs. 13a and 19a), and the scheme seems to have achieved a similar level of success. The results presented in this section are very encouraging and clearly indicate that the $T_{e}$ parameterization scheme is robust.

\section{Discussion and conclusions}

In this study, we attempt to improve SSTA simulations of an intermediate ocean model recently developed by Keenlyside and Kleeman (2002). In the original model, the simulated SST variability is underestimated, particularly over the central Pacific basin. Comparison with a comprehensive OGCM simulation suggests that the problem is associated with the parameterization of the subsurface temperature entrained

FIG. 15. Anomaly correlation between simulated and observed SST anomalies calculated during (left panels) the period 1963-79 and during (right panels) the period 1980-96, respectively. The simulated SST anomalies are obtained with the SVD-based seasonally (a), (c) invariant and (b), (d) varying $T_{e}$ versions of the $T_{e}$ model. The time series at each point have been smoothed by a 5-month running mean filter. The contaour interval is 0.1 . 

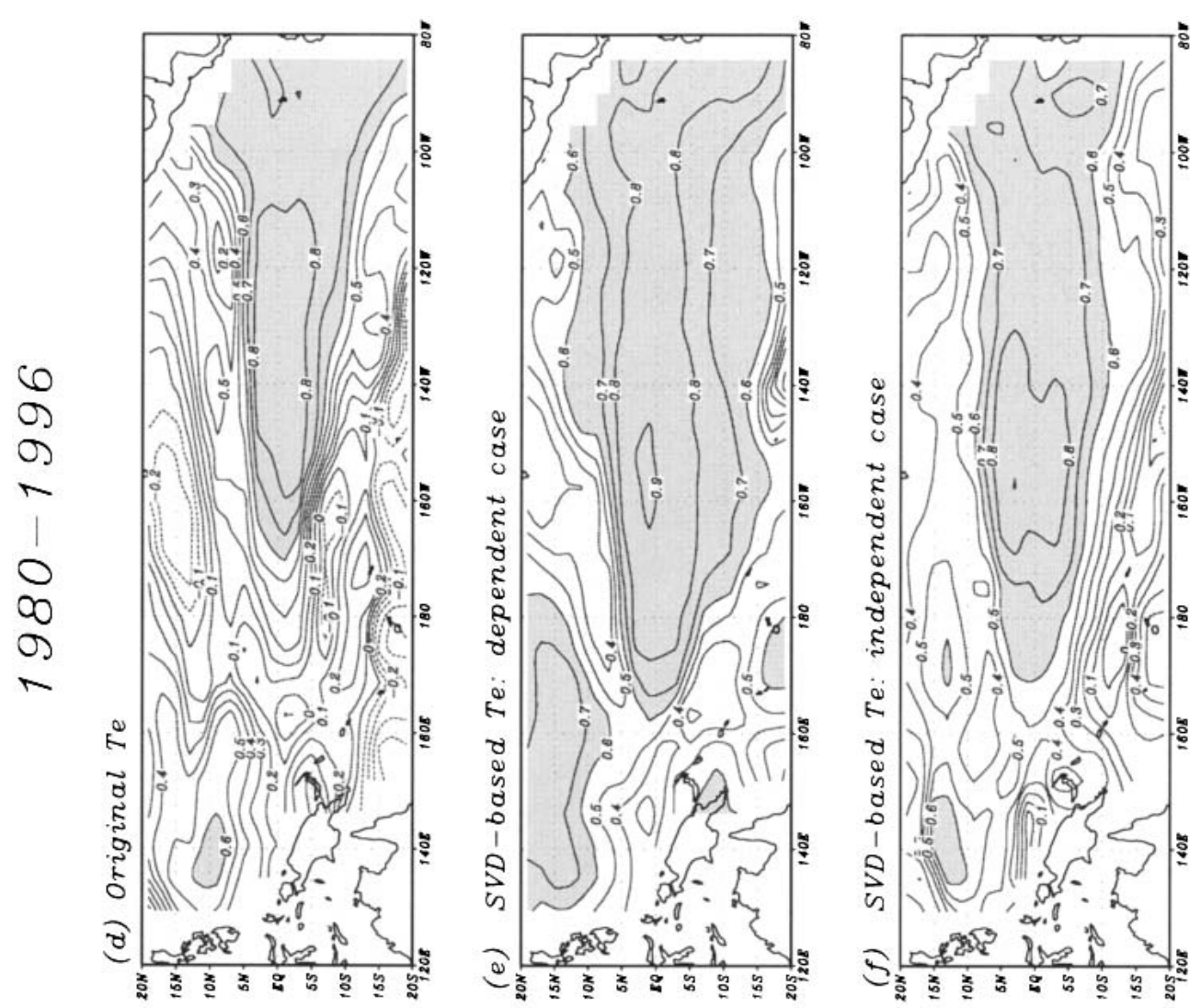

노몽 

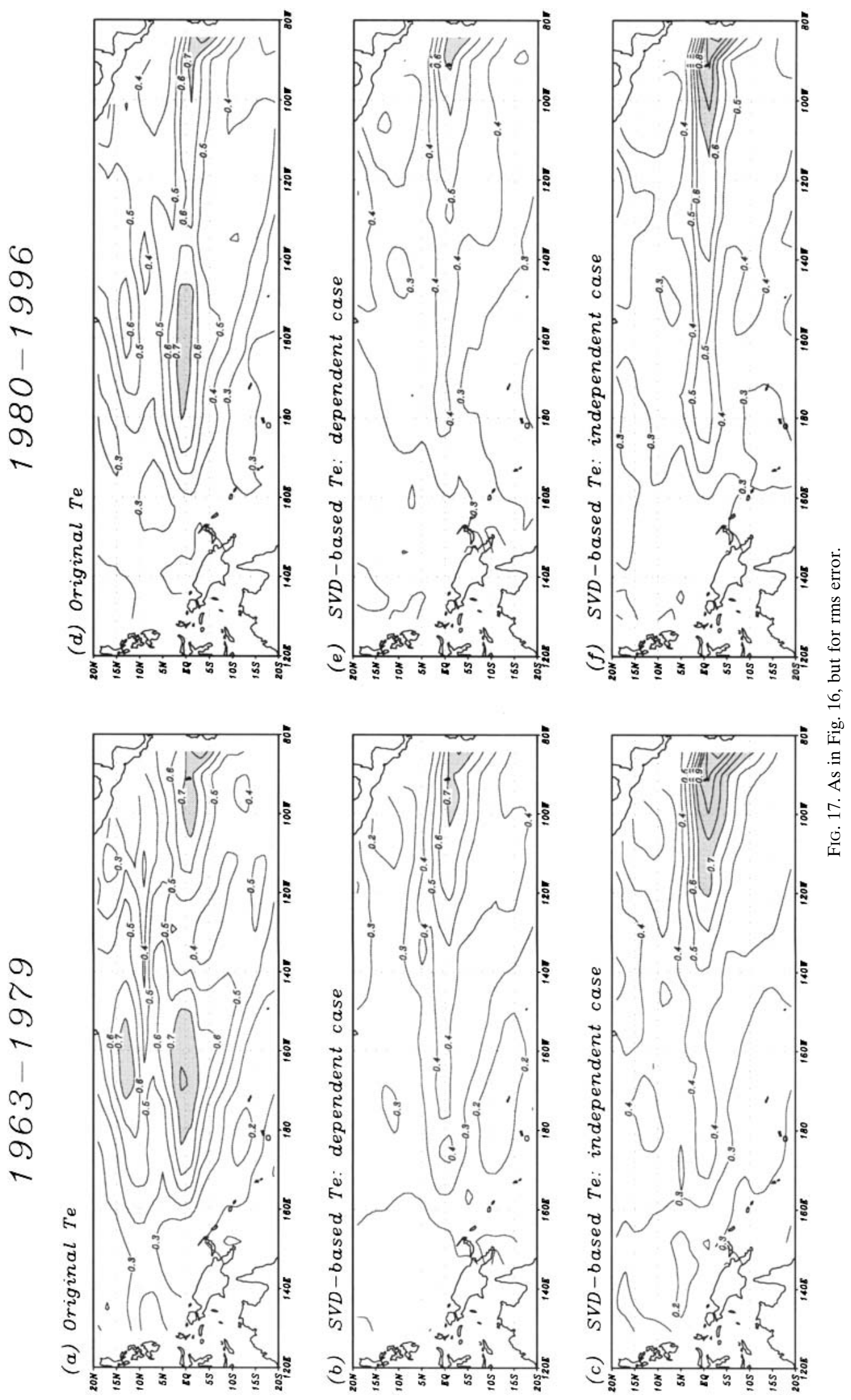
(a) During period 1980-1996

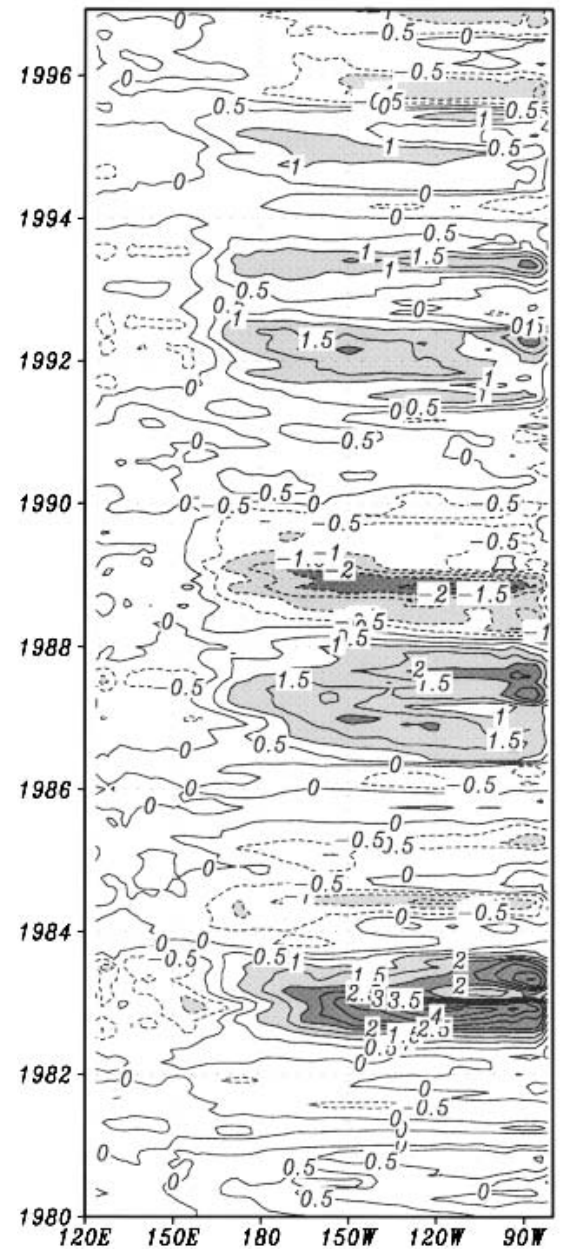

(b) During period 1997-2002

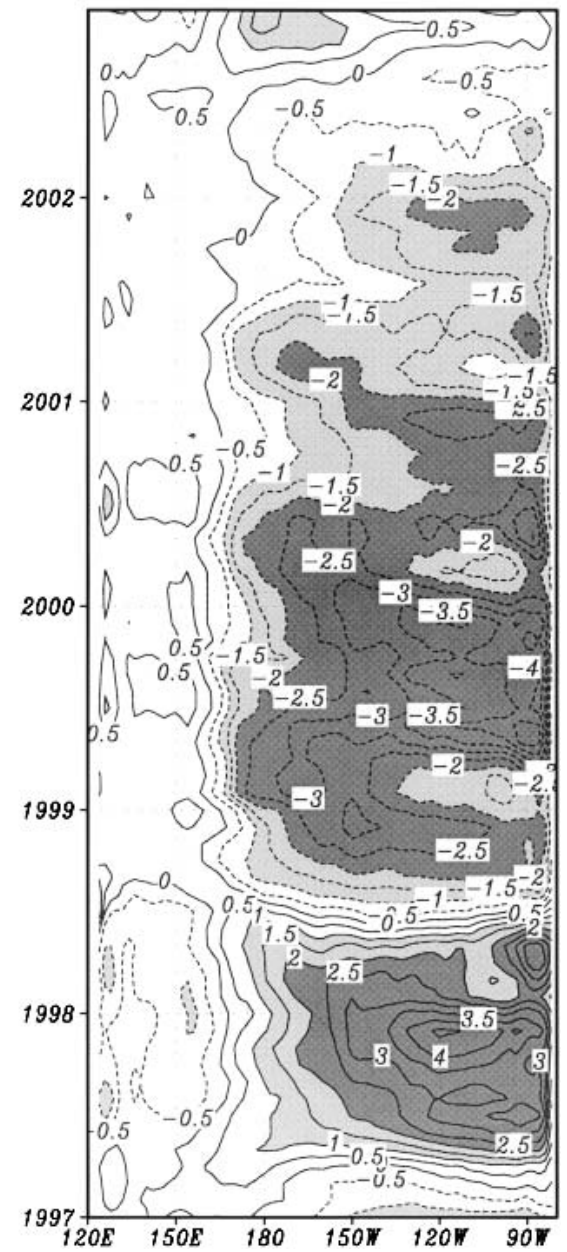

FIG. 18. Simulated SST anomalies along the equator during the periods (left column) 1980-96 and (right column) 1997-2002; the model is forced by the FSU wind anomalies using the SVD-based seasonally varying $T_{e}$ model that is constructed from the NCEP-NCAR wind simulation. The contour interval is $0.5^{\circ} \mathrm{C}$.

into the surface mixed layer, a major process affecting interannual variability of SST in the equatorial Pacific.

Here, an empirical $T_{e}$ parameterization scheme is proposed for better SSTA simulations in the equatorial Pacific. The scheme is developed in two steps. First, inverse modeling is used to estimate $T_{e}$ from an SSTA equation, using observed (SST fields and their tendency) and model data (mean and anomaly currents). This inverse approach incorporates observations and models in a consistent way to allow the best estimate of $T_{e}$ possible: best in the sense that it is exactly the $T_{e}$ field required by the model to perfectly simulate the observed SST. Second, using a SVD of the covariance between SSH anomalies simulated from the dynamical ocean model and $T_{e}$ anomalies estimated from the inverse modeling, a $\mathrm{SSH}-T_{e}$ relationship is developed, allowing the major features of interannual variability associated with El Niño and La Niña events to be cap- tured. This procedure is able to better parameterize $T_{e}$ anomaly fields than other local schemes, including the phase lag relationship between $T_{e}$ and $\mathrm{SSH}$ variability over the central equatorial Pacific. As a result, $T_{e}$ variability is significantly improved, with reasonable amplitude and structure over the tropical Pacific. In particular, the phase lag of $T_{e}$ variations relative to those in SSH over the central equatorial Pacific is realistically simulated. An improved $T_{e}$ parameterization naturally leads to better depiction of the subsurface influence on SST variability by the mean upwelling against subsurface temperature anomalies. As such, the model produces good SSTA simulations in the tropical Pacific basin. The robustness and effectiveness of the new empirical scheme are demonstrated by various validation experiments.

There are two potential concerns with the proposed empirical procedure. Since no reliable, basinwide $T_{e}$ 


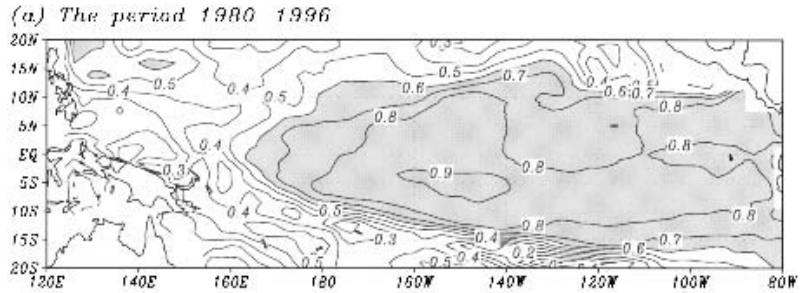

(b) The perius 1997-2002

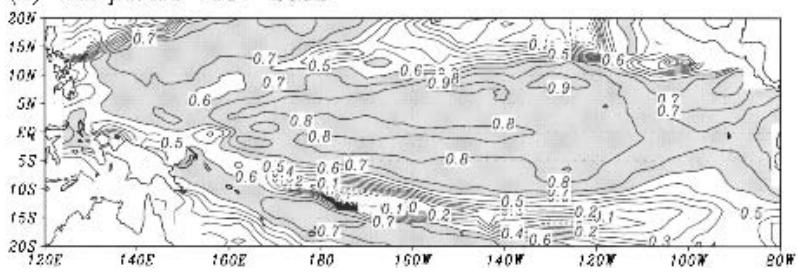

FIG. 19. Anomaly correlation between simulated and observed SST anomalies separately calculated during the periods (a) 1980 96 and (b) 1997-2002. The model is forced by the FSU wind anomalies using the SVD-based seasonally varying $T_{e}$ model constructed from the NCEP-NCAR wind simulation. The time series at each point have been smoothed by a 5-month running mean filter. The contour interval is 0.1 .

observations are available at present, the SSTA model has been used together with observations of SST to infer the values of $T_{e}$ in the tropical Pacific. This inverse modeling approach is conceived as a means for calculating the temperature of subsurface water entrained into the mixed layer in a balanced way, adjusting the various terms of the heat budget in the surface layer. Thus, by definition, the resultant $T_{e}$ anomaly fields give rise to perfect SSTA simulations. In so doing, however, any systematic errors are effectively incorporated into the inferred $T_{e}$ field, possibly resulting in a biased estimate. Fortunately, subsurface thermal variability associated with ocean dynamical adjustment is a dominant forcing of SST variability in the equatorial Pacific on interannual time scales. Thus, it can be expected that this inverse modeling approach will give a useful estimate of $T_{e}$ anomalies. The second concern involves the estimation of $T_{e}$ from SSH anomalies using a SVD technique. This approach is justified, since there exists a good relationship between $T_{e}$ and SSH anomalies in the equatorial Pacific on interannual time scales. However, SSH may not be the only factor contributing to $T_{e}$ variability; other local thermodynamics may also be important. Thus, the correlation between SSH and $T_{e}$ may be influenced by many spatially and temporally varying processes. A parameterization of $T_{e}$ in terms of SSH from historical data implies that any processes contributing to $T_{e}$ variability will be automatically included in the scheme, in so far as these processes are reflected in the SSH anomalies. This may also lead to a biased estimation for $T_{e}$. The results indicate that these possible aliasing problems are not serious in parameterizing $T_{e}$ from SSH anomalies. As has been shown, the $T_{e}$ anomalies estimated in this way appear to be quite rea- sonable, in good agreement with those from the OGCM. Furthermore, the success of the scheme in improving SSTA simulations is a good justification.

To date, various approaches have been introduced to improve model simulations and predictions of tropical Pacific SSTAs. For example, model output statistics (MOS) corrections have been tested and implemented in postprocessing model results (e.g., Barnett et al. 1993). In this regard, the empirical procedure to improve SSTA simulations developed here can be viewed as an interactive correction approach, balancing the relative role of $T_{e}$ perturbations versus surface current perturbations in determining SST variability. This balanced treatment of various terms in the SSTA equation provides the possibility for this model to produce better SSTA simulations.

Further improvements and applications of the scheme are under way in several directions. In particular, a better heat flux formulation is needed in the inverse modeling for determining $T_{e}$, instead of the damping formulation used in this paper. The procedure can also be readily applied to a hybrid system previously introduced (Zhang and Zebiak 2003) in which a separate SSTA model is explicitly embedded into a $z$ coordinate OGCM to enhance the thermocline effect on SST variability over the equatorial Pacific.

The SSTA-improved KK ocean model is very promising for coupled experiments and predictions of $\mathrm{El}$ Niño. Actually, this ocean model has been coupled to a statistical atmospheric model estimating wind stress changes, which is also based on a SVD analysis between observed SST and wind stress anomalies. The coupled system exhibits a variety of behaviors for a range of parameters that are in good agreement with observations (Zhang et al. 2003). Retrospective El Niño predictions and real-time forecasts with this intermediate coupled system are also being conducted (Zhang et al. 2003). Detailed results will be presented elsewhere.

Acknowledgments. We would like to thank D. DeWitt, D. Chen, T. Barnston, A. J. Busalacchi, R. Murtugudde, Y. Tang, F. F. Jin, and B. Wang for their comments and suggestions. RHZ is indebted to P. Chang for his early help in the SVD-based statistical analysis. The authors wish to thank the anonymous reviewers for their numerous comments that helped to improve the original manuscript. This research is supported by the IRI and its sponsors, and by NSF Grant 25-74200-F0960 (RK) and NASA Grant 25-74200F5044 (RK).

\section{REFERENCES}

Barnett, T. P., M. Latif, E. Kirk, and E. Roeckner, 1991: On ENSO physics. J. Climate, 4, 487-515.

, — N. Nraham, M. Flugel, S. Pazan, and W. White, 1993: ENSO and ENSO-related predictability. Part I: Prediction of equatorial Pacific sea surface temperature with a hybrid coupled ocean-atmosphere model. J. Climate, 6, 1545-1566. Barnston, A. G., M. H. Glantz, and Y. He, 1999: Predictive skill of 
statistical and dynamical climate models in SST forecasts during the 1997-98 El Niño episode and the 1998 La Niña onset. Bull. Amer. Meteor. Soc., 80, 217-243.

Bourassa, M. A., S. R. Smith, and J. J. O'Brien, 2001: A new FSU wind and flux climatology. Preprints, 11th Conf. on Interactions of the Sea and Atmosphere, San Diego, CA, Amer. Meteor. Soc., CD-ROM, 103.

Busalacchi, A. J., and J. J. O'Brien, 1980: The seasonal variability in a model of the tropical Pacific. J. Phys. Oceanogr., 10, 1929-1951.

Cane, M. A., and S. E. Zebiak, 1985: A theory for El Niño and Southern Ocillation. Science, 228, 1084-1087.

Canuto, V. M., A. Howard, Y. Cheng, and M. S. Dubovikov, 2001: Ocean turbulence. Part I: One-point closure model-momentum and heat vertical diffusivities. J. Phys. Oceanogr., 31, 1413-1426.

Chang, P., L. Ji, and R. Saravanan, 2001: A hybrid coupled model study of tropical Atlantic variability. J. Climate, 14, 361-390.

Chen, D., L. M. Rothstein, and A. J. Busalacchi, 1994: A hybrid vertical mixing scheme and its application to tropical ocean models. J. Phys. Oceanogr., 24, 2156-2179.

_ , S. E. Zebiak, A. J. Busalacchi, and M. A. Cane, 1995: An improved procedure for El Niño forecasting: Implications for predictability. Science, 269, 1699-1702.

- M. A. Cane, S. E. Zebiak, R. Canizares, and A. Kaplan, 2000: Bias correction of an ocean-atmosphere coupled model. Geophys. Res. Lett., 27, 2585-2588.

,,-- A. Kaplan, S. E. Zebiak, and D. Huang, 2004: Predictability of El Niño over the past 148 years. Nature, 428, 733-736.

DeWitte, B., D. Gushchina, Y. duPenhoat, and S. Lakeev, 2002: On the importance of subsurface variability for ENSO simulation and prediction with intermediate coupled models of the tropical Pacific: A case study for the 1997-1998 El Niño. Geophys. Res. Lett., 29, 1666, doi:10.1029/2001GL014452.

Goldenberg, S., and J. J. O'Brien, 1981: Time and space variability of the tropical Pacific wind stress. Mon. Wea. Rev., 109, 11901207.

Ji, M., D. W. Behringer, and A. Leetmaa, 1998: An improved coupled model for ENSO prediction and implications for ocean initialization. Part II: The coupled model. Mon. Wea. Rev., 126, 1022-1034.

Jin, F.-F., and S.-I. An, 1999: Thermocline and zonal adjective feedbacks within the equatorial ocean recharge oscillator model for ENSO. Geophys. Res. Lett., 26, 2989-2992.

Kalnay, E., and Coauthors, 1996: The NCEP/NCAR 40-Year Reanalysis Project. Bull. Amer. Meteor. Soc., 77, 437-471.

Kang, I.-S., and J.-S. Kug, 2000: An El Niño prediction system using an intermediate ocean and a statistical atmosphere. Geophys. Res. Lett., 27, 1167-1170.

Keenlyside, N., 2001: Improved modeling of zonal currents and SST in the tropical Pacific. Ph.D. thesis, Monash University, 193 pp.

- and R. Kleeman, 2002: On the annual cycle of the zonal currents in the equatorial Pacific. J. Geophys. Res., 107, 3093, doi:10.1029/2000JC0007111.

Kleeman, R., 1993: On the dependence of hindcast skill on ocean thermodynamics in a coupled ocean-atmosphere model. $J$. Climate, 6, 2012-2033.

— R. Colman, N. Smith, and S. Power, 1996: A recent change in the mean state of the Pacific basin climate: Observational evidence and atmospheric and oceanic response. J. Geophys. Res., 101, 20 483-20 499.

Large, W. G., and P. R. Gent, 1999: Validation of vertical mixing in an equatorial ocean model using large eddy simulations and observations. J. Phys. Oceanogr., 29, 449-464.

, G. Danabasoglu, S. C. Doney, and J. C. McWilliams, 1997: Sensitivity to surface forcing and boundary layer mixing in a global ocean model: Annual mean climatology. J. Phys. Oceanogr., 27, 2418-2447.
Latif, M., and Coauthors, 1998: A review of the predictability and prediction of ENSO. J. Geophys. Res., 103, 14 375-14 393.

- , and Coauthors, 2001: ENSIP: The El Niño Simulation Intercomparison Project. Climate Dyn., 18, 255-276.

Levitus, S., 1982: Climatological Atlas of the World Ocean. NOAA Prof. Paper 13, 173 pp. and 17 microfiche.

McCreary, J. P., 1981: A linear stratified ocean model of the equatorial undercurrent. Philos. Trans. Roy. Soc. London, 298, 603-635.

_ , and D. L. T. Anderson, 1991: An overview of coupled ocean-atmosphere models of El Niño and the Southern Oscillation. J. Geophys. Res., 96, 3125-3150.

Miller, A. J., T. P. Barnett, and N. E. Graham, 1993: A comparison of some tropical ocean models: Hindcast skill and El Niño evolution. J. Phys. Oceanogr., 23, 1567-1591.

Murtugudde, R., R. Seager, and A. J. Busalacchi, 1996: Simulation of tropical oceans with an ocean GCM coupled to an atmospheric mixed layer model. J. Climate, 9, 1795-1815.

Neelin, J. D., and F.-F. Jin, 1993: Modes of interannual tropical ocean-atmosphere interaction a united view. Part II: Analytical results in the weak-coupling limit. J. Atmos. Sci., 50, 3504-3522. , and Coauthors, 1992: Tropical air-sea interactions in general circulation models. Climate Dyn., 7, 73-104.

Pacanowski, R. C., and S. M. Griffies, 1998: MOM 3.0 manual. NOAA/Geophysical Fluid Dynamics Laboratory, $700 \mathrm{pp}$.

Perigaud, C., and B. DeWitte, 1996: El Niño-La Niña events simulated with Cane and Zebiak's model and observed with satellite or in situ data. Part I: Model data comparison. $J$. Climate, 9, 65-84.

Reynolds, R. W., N. A. Rayner, T. M. Smith, D. C. Stokes, and W. Wang, 2002: An improved in situ and satellite SST analysis for climate. J. Climate, 15, 1609-1625.

Seager, R., M. Blumenthal, and Y. Kushinir, 1995: An advective atmospheric mixed layer model for ocean modeling purposes: Global simulation of surface heat fluxes. J. Climate, 8, 19511964.

Stockdale, T. N., A. J. Busalacchi, D. E. Harrison, and R. Seager, 1998: Oceanic modeling of ENSO. J. Geophys. Res., 103, $14325-14355$

Syu, H.-H., J. D. Neelin, and D. Gutzler, 1995: Seasonal and interannual variability in a hybrid coupled GCM. J. Climate, 8, 2121-2143.

Wallcraft, A. J., A. B. Kara, H. E. Hurlburt, and P. A. Rochford, 2003: The NRL Layered Global Ocean Model (NLOM) with an embedded mixed layer submodel: Formulation and tuning. J. Atmos. Oceanic Technol., 20, 1601-1615.

Wang, W., and M. J. McPhaden, 2000: The surface-layer heat balance in the equatorial Pacific Ocean. Part II: Interannual variability. J. Phys. Oceanogr., 30, 2989-3008.

Zebiak, S. E., and M. A. Cane, 1987: A model El Niño/Southern Oscillation. Mon. Wea. Rev., 115, 2262-2278.

Zhang, R.-H., and S. Levitus, 1997: Interannual variability of the coupled tropical Pacific ocean-atmospheric system associated with the El Niño-Southern Oscillation. J. Climate, 10, 1312-1330.

_ and S. E. Zebiak, 2002: Effect of penetrating momentum flux over the surface boundary/mixed layer in a $z$-coordinate OGCM of the tropical Pacific. J. Phys. Oceanogr., 32, 36163637.

$\longrightarrow$, and — 2003: Embedding a SST anomaly model into a $z$-coordinate oceanic GCM for producing El Niño Oscillation in the tropical Pacific Climate system. Geophys. Res. Lett., 30, 1176, doi:10.1029/2002GL015428.

, T. Kagimoto, and S. E. Zebiak, 2001: Subduction of decadal North Pacific thermal anomalies in an ocean GCM. Geophys. Res. Lett., 28, 2449-2452.

_ R. Kleeman, and N. Keenlyside, 2003: A new intermediate coupled model for El Niño simulation and prediction. Geophys. Res. Lett., 30, 2012, doi:10.1029/ 2003GL018010. 